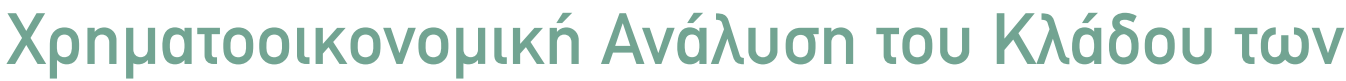

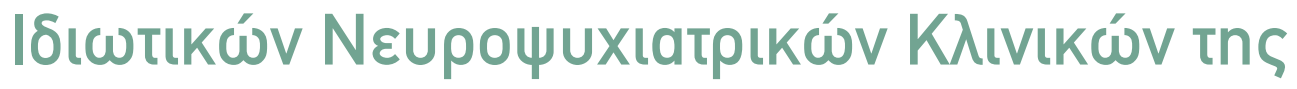

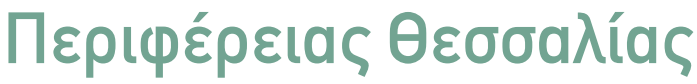

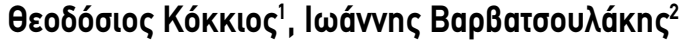

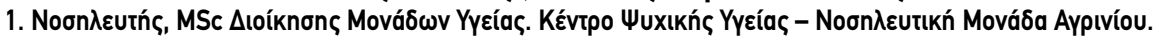

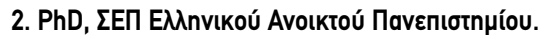

\section{ПЕРIАНЧH}

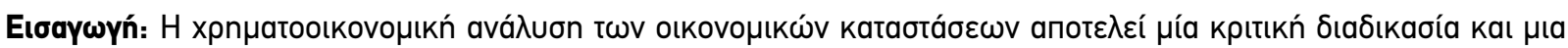

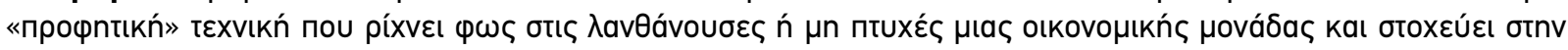

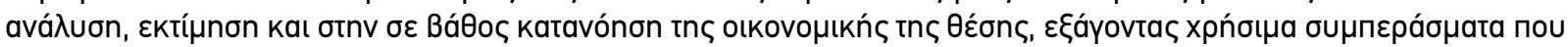

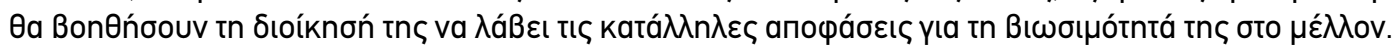

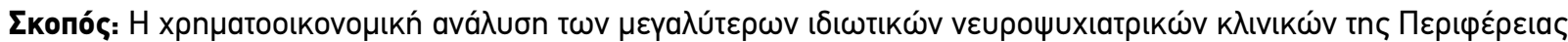

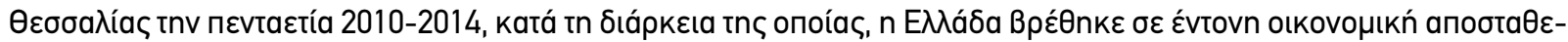

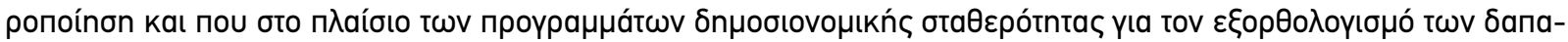

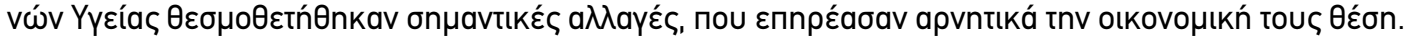

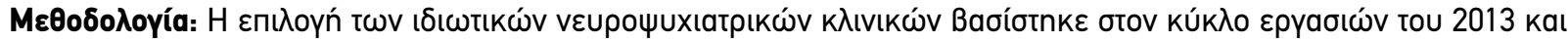

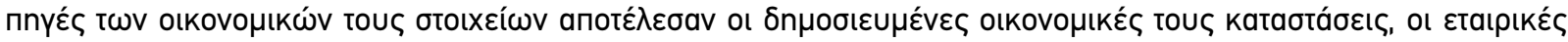

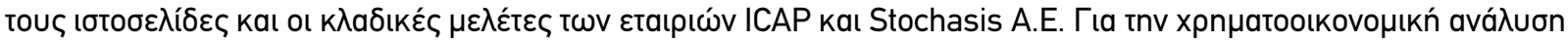

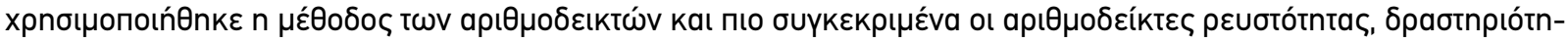

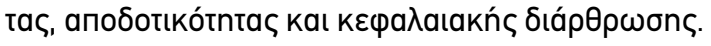

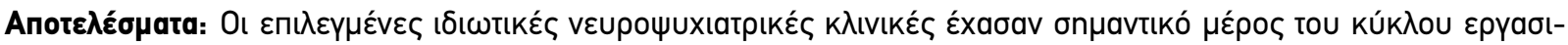

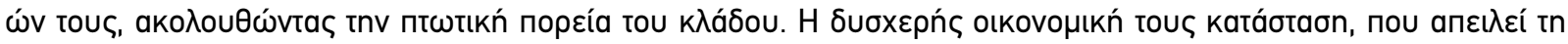

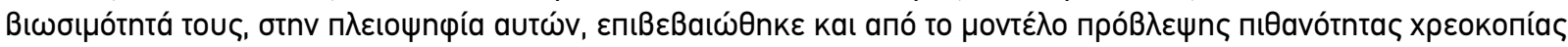

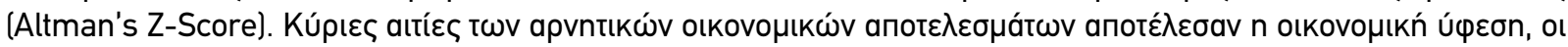

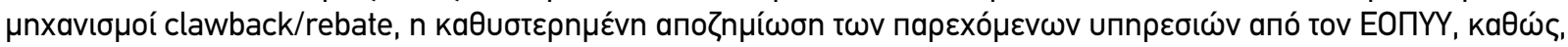

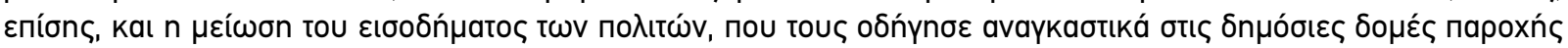

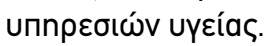

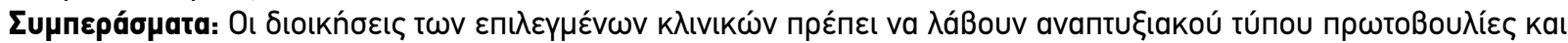

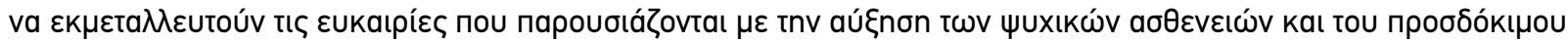

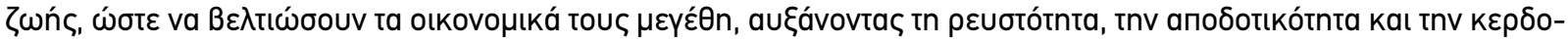
фopía tous.

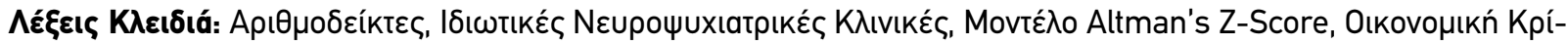

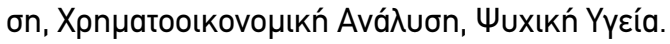




\section{EPEYNHTIKA APOPA}

\section{BAEIKA EHMEIA}

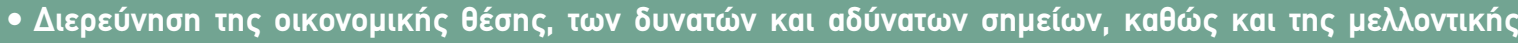

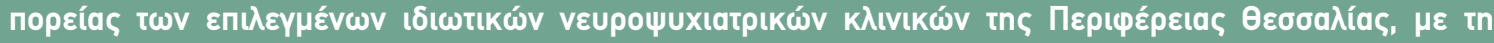

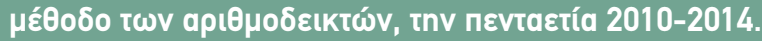

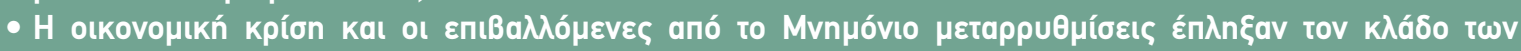

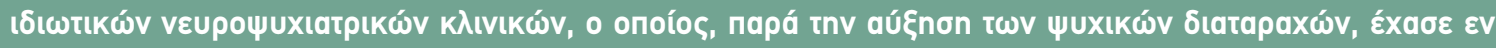

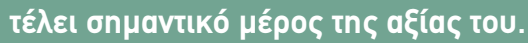

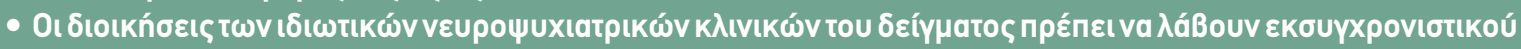
túnou пр

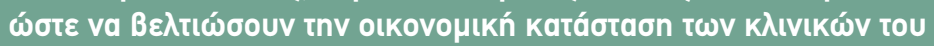

\section{INTRODUCTION}

H

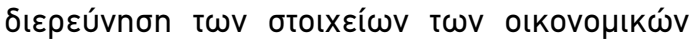

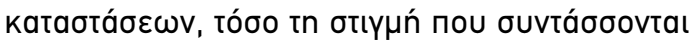

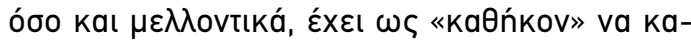

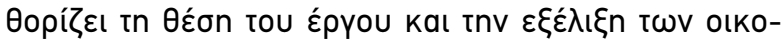

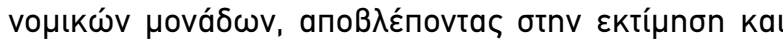

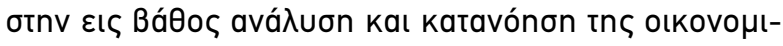

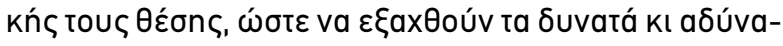

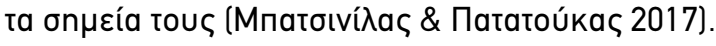

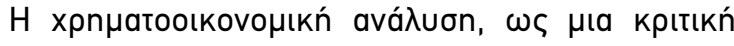

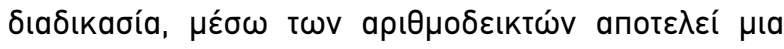

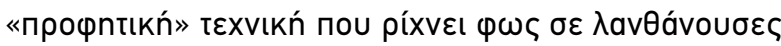

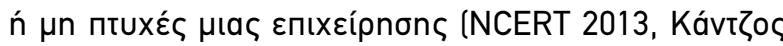

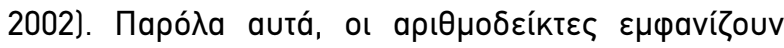

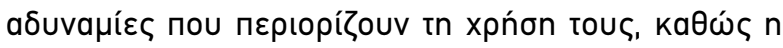

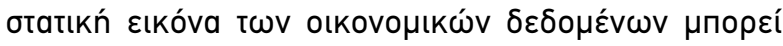

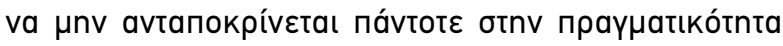

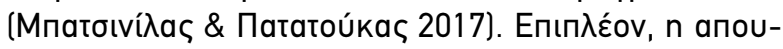

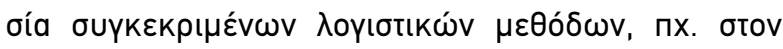

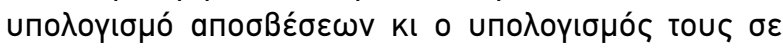

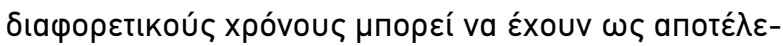

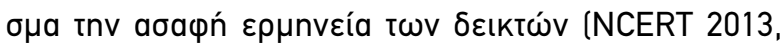

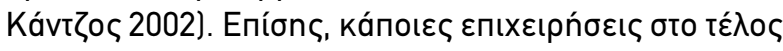

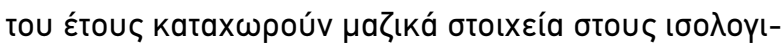

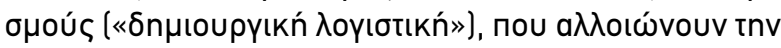

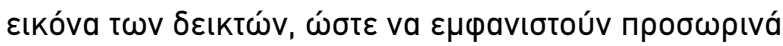

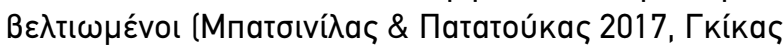

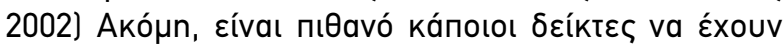

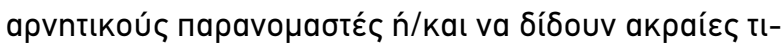

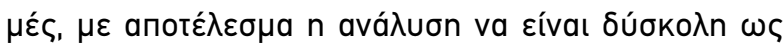

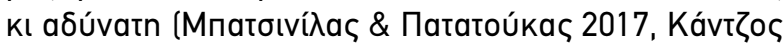

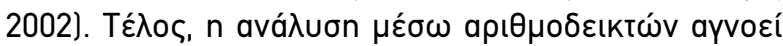

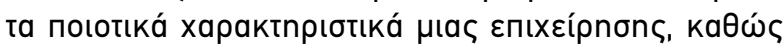

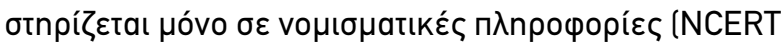

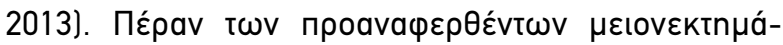

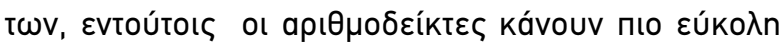

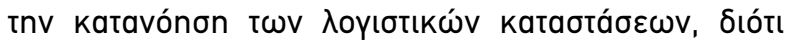

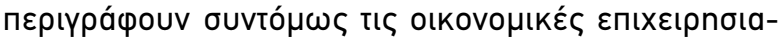

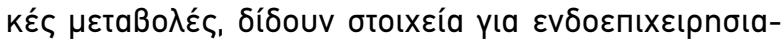

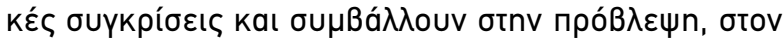

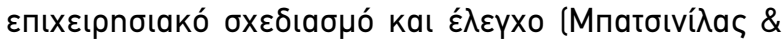

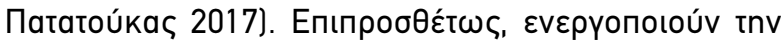

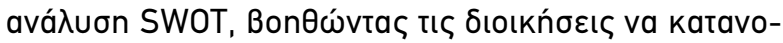

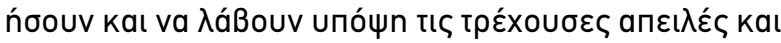

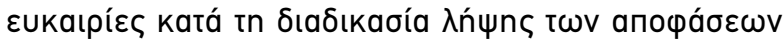

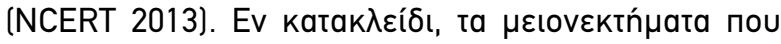

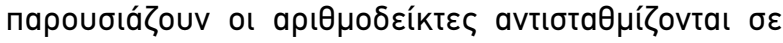

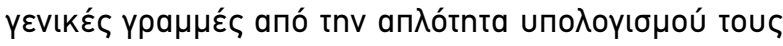
(Папаס́́ac 2015).

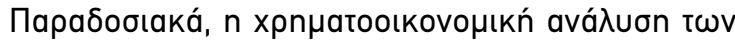

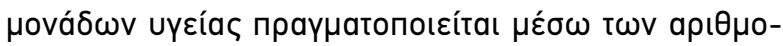

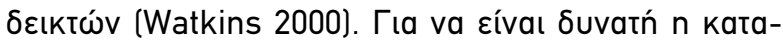

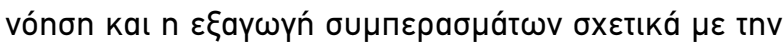

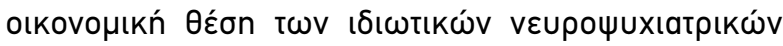

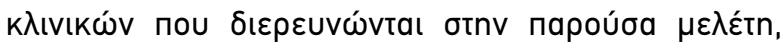

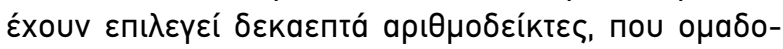

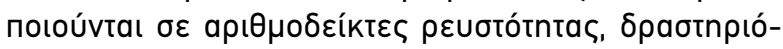

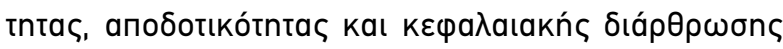

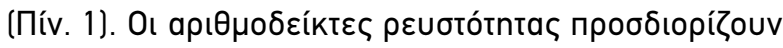

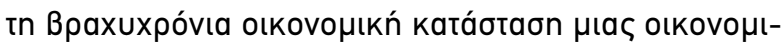

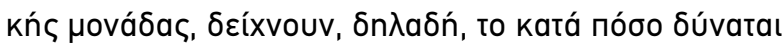

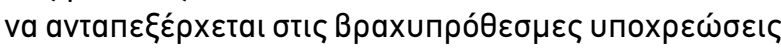

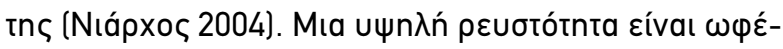

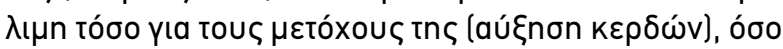

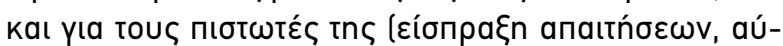

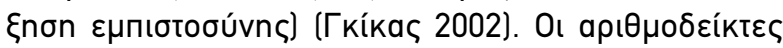

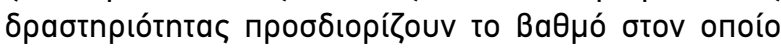

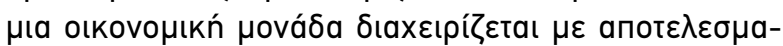

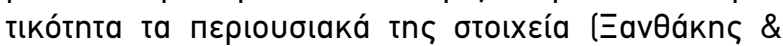

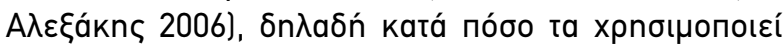

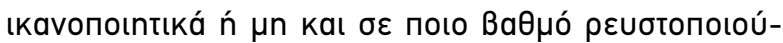

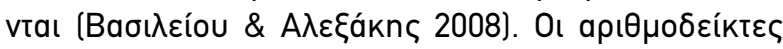

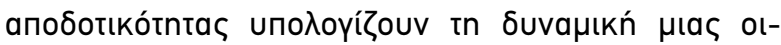

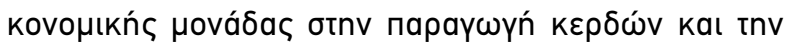




\section{EPEYNHTIKA APOPA}

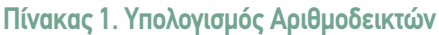

\begin{tabular}{|c|c|c|c|}
\hline \multicolumn{4}{|c|}{ 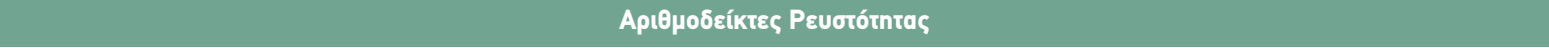 } \\
\hline 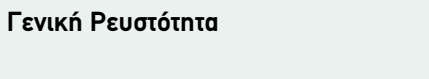 & 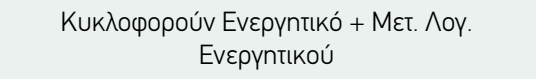 & l & 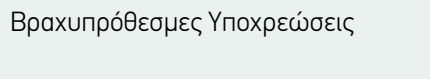 \\
\hline 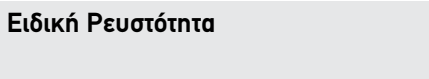 & 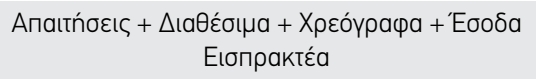 & l & 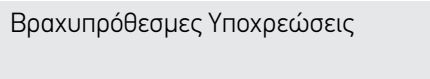 \\
\hline 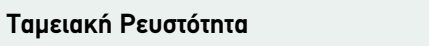 & 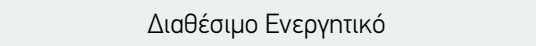 & l & 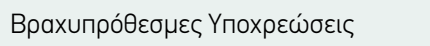 \\
\hline 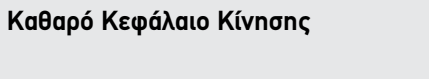 & 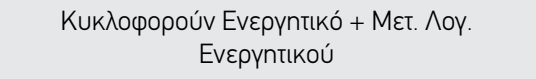 & - & 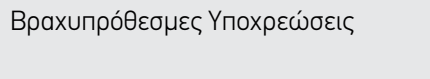 \\
\hline \multicolumn{4}{|c|}{ 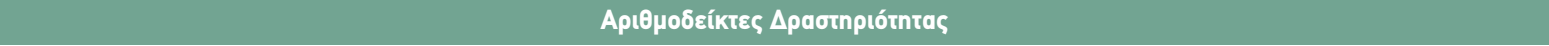 } \\
\hline 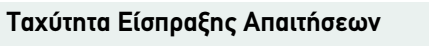 & 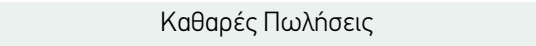 & l & 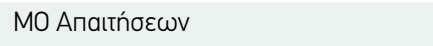 \\
\hline 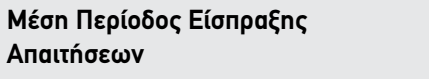 & 365 & l & 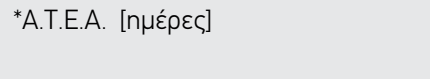 \\
\hline 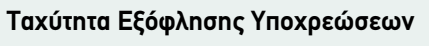 & 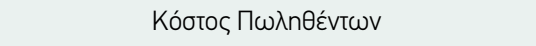 & l & 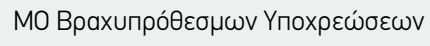 \\
\hline 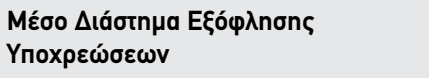 & 365 & l & 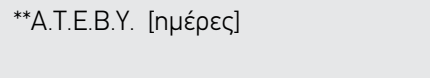 \\
\hline 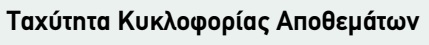 & 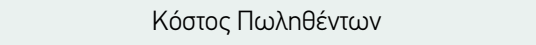 & l & 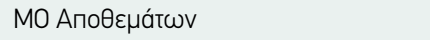 \\
\hline 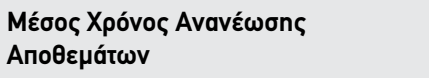 & 365 & l & 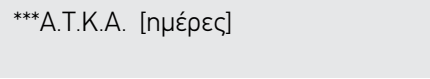 \\
\hline \multicolumn{4}{|c|}{ 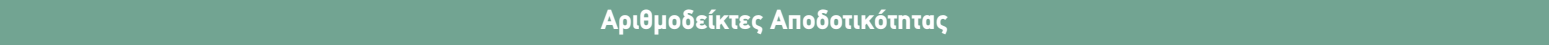 } \\
\hline 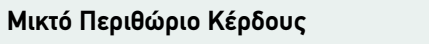 & 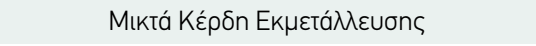 & l & 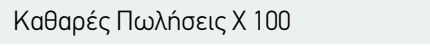 \\
\hline 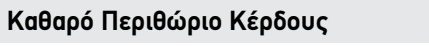 & KaӨapá Képon & l & 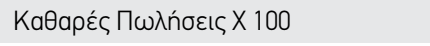 \\
\hline 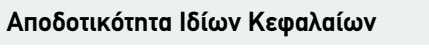 & KaӨapá Képon & l & 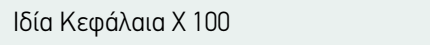 \\
\hline 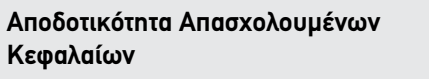 & 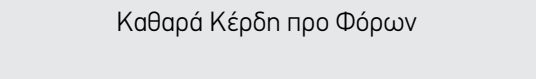 & l & ПаӨntıkó X 100 \\
\hline \multicolumn{4}{|c|}{ 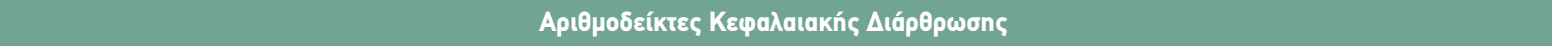 } \\
\hline$\Delta$ aveıakń Enıßápuvon & 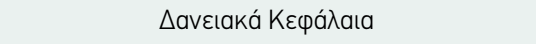 & l & 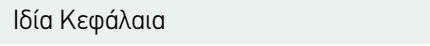 \\
\hline 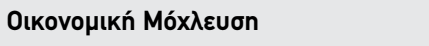 & 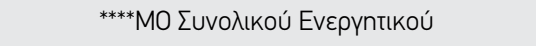 & l & 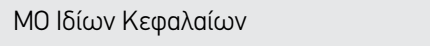 \\
\hline BaӨpós Паүıопoínons & Пáyıo Evepүntıкó & l & 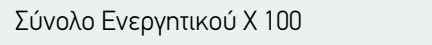 \\
\hline \multicolumn{4}{|c|}{ Altman's Z-Score } \\
\hline 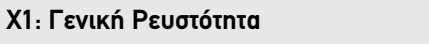 & 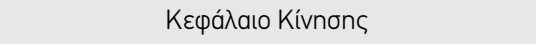 & l & 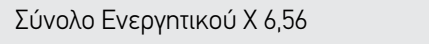 \\
\hline 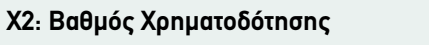 & 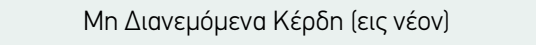 & l & 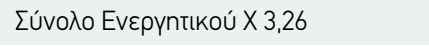 \\
\hline 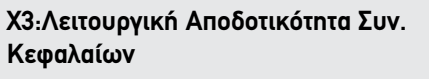 & 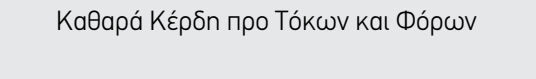 & l & 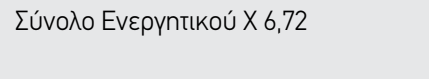 \\
\hline 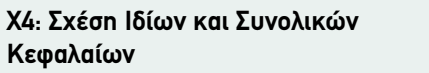 & 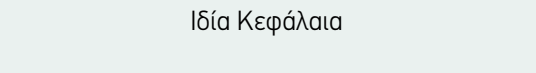 & l & 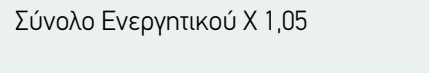 \\
\hline
\end{tabular}

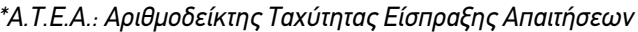

${ }^{* *}$ A.T.E.B.Y.: A

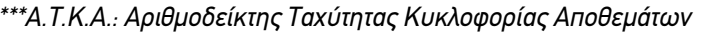

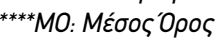




\section{EPEYNHTIKA APOPA}

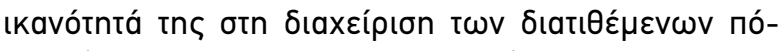

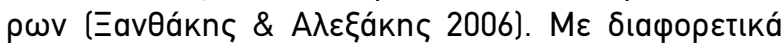

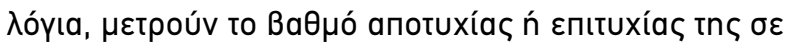

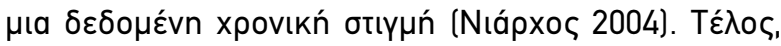

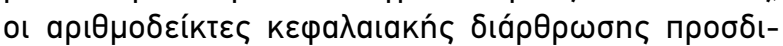

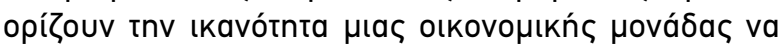

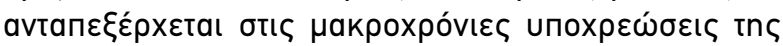

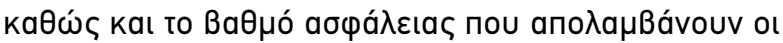

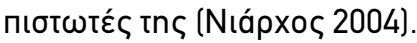

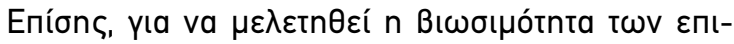

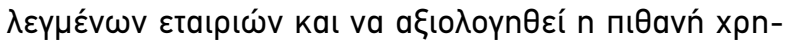

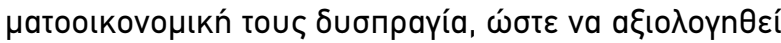

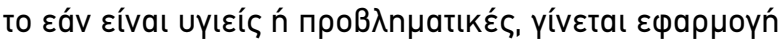

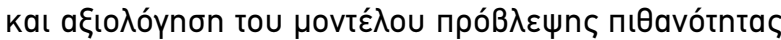

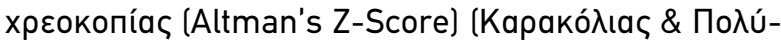

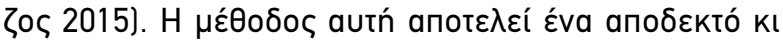

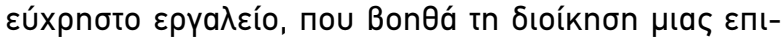
xeípnon

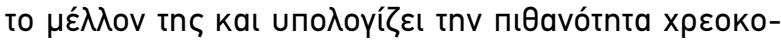

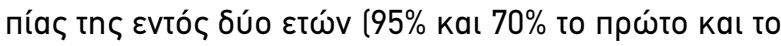

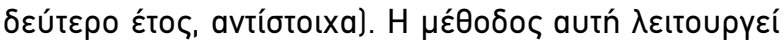

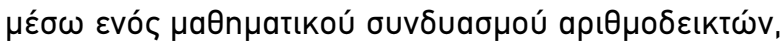

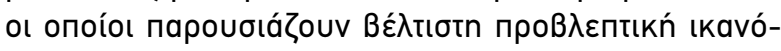

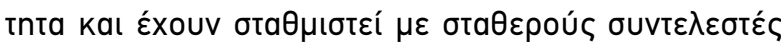

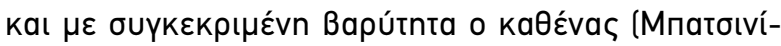

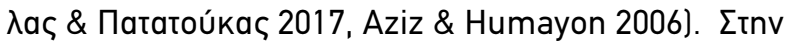

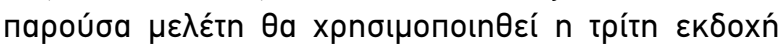

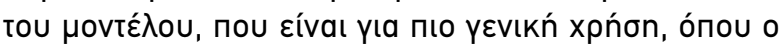

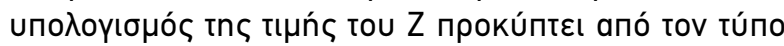
$Z=6,56 \times X_{1}+3,26 \times X_{2}+6,72 \times X_{3}+1,05 \times X_{4}$ (Пív. 1),

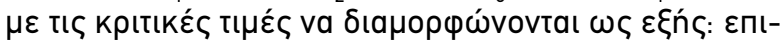

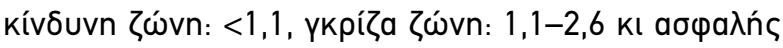

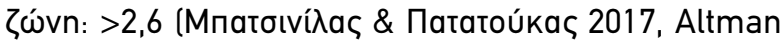
1968).

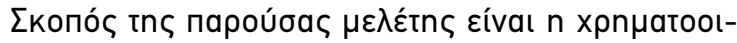

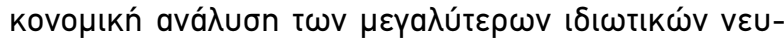

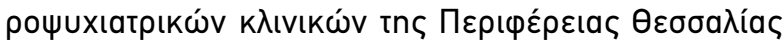

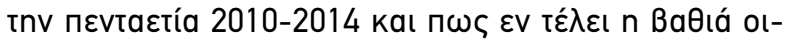

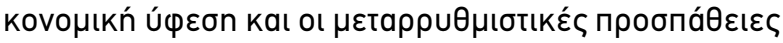

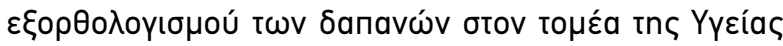

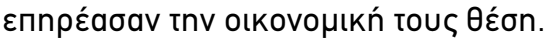

\section{MEӨO $\triangle 0 \wedge 0 Г I A$}

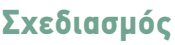

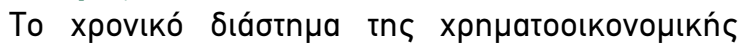

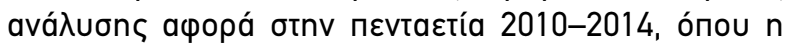

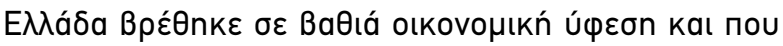

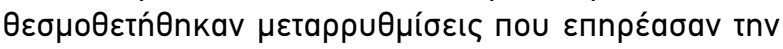

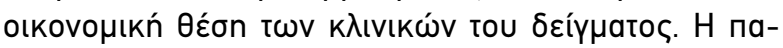

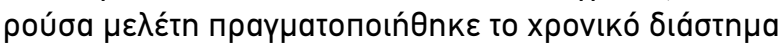

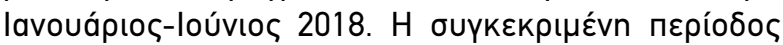

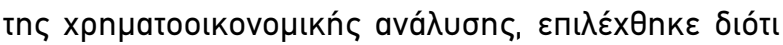

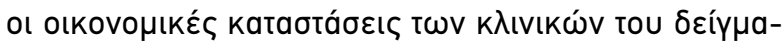

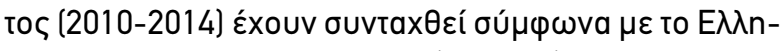

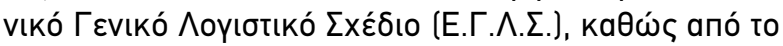

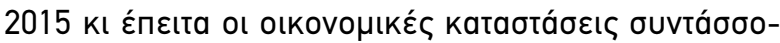

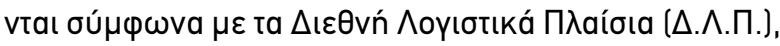

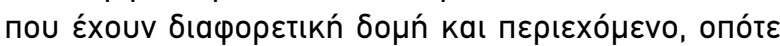

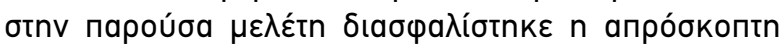

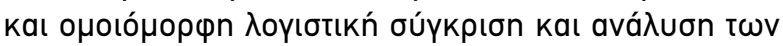

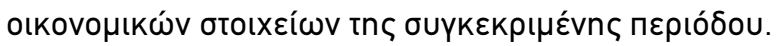

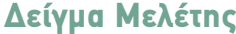

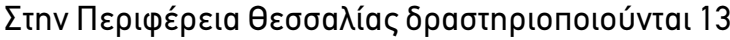

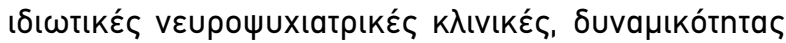

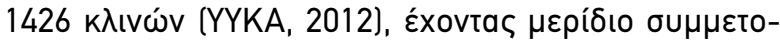

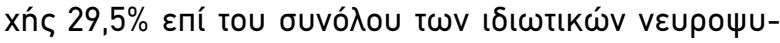

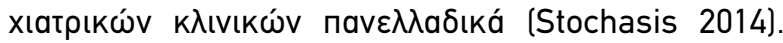

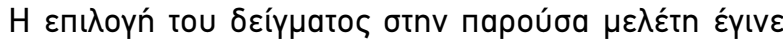

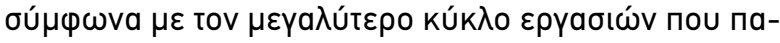

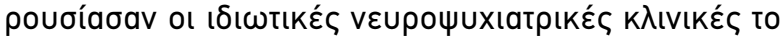

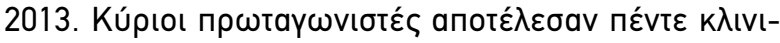

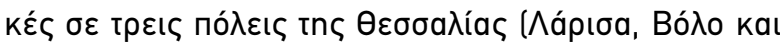

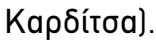

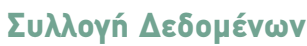

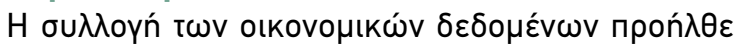

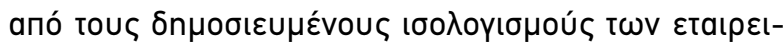

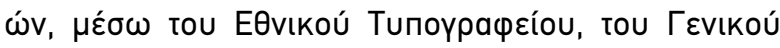

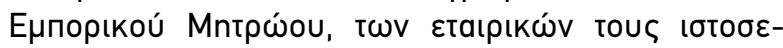

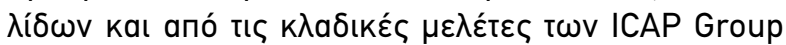
(2015) kaı Stochasis A.E. (2014).

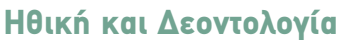

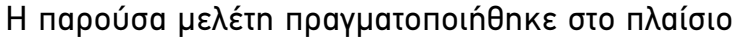

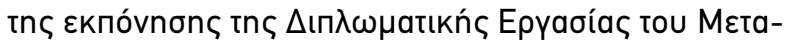

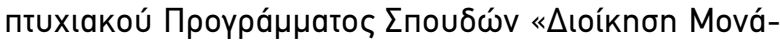

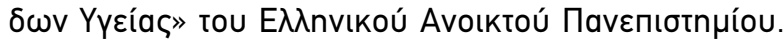

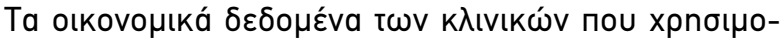

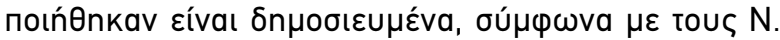

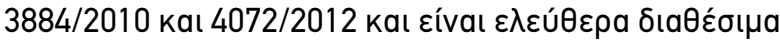

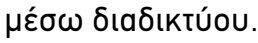

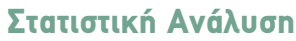

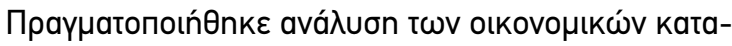

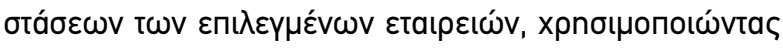

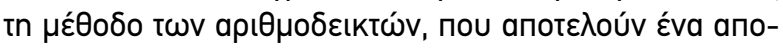

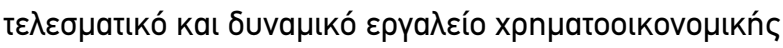

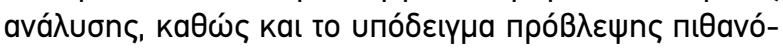

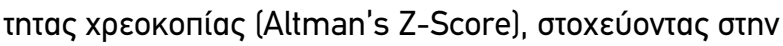

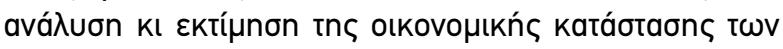

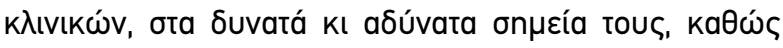

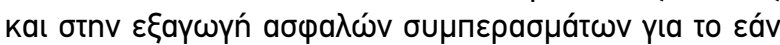

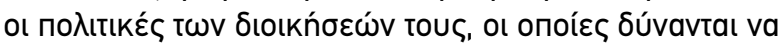

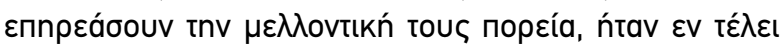

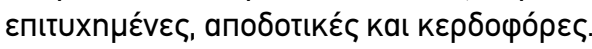




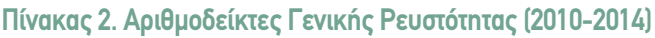

\begin{tabular}{|c|c|c|c|c|c|c|c|}
\hline 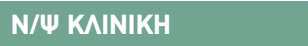 & 2010 & 2011 & 2012 & 2013 & 2014 & M.0. & \% METABONH \\
\hline ІППОКРАТЕІО (к入ıvıкń 1) & 3,43 & 6,65 & 6,16 & 9,17 & 9,72 & 7,03 & $+183,38 \%$ \\
\hline 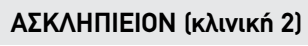 & 1,41 & 1,57 & 1,29 & 1,51 & 0,90 & 1,34 & $-36,17 \%$ \\
\hline 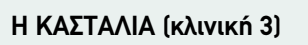 & $M / \Delta$ & 1,01 & 1,11 & 2,09 & 1,49 & 1,42 & $+47,52 \%$ \\
\hline 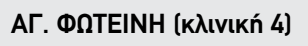 & 2,57 & 3,27 & 3,53 & 3,79 & 4,02 & 3,44 & $+56,42 \%$ \\
\hline 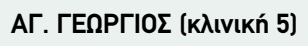 & 1,27 & 1,51 & 1,38 & 1,45 & 1,00 & 1,32 & $-21,26 \%$ \\
\hline M.O. K\A $\Delta O Y$ & 1,44 & 2,09 & 1,79 & 2,10 & 2,16 & 1,92 & $+50,00 \%$ \\
\hline
\end{tabular}

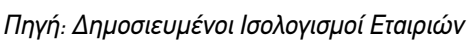

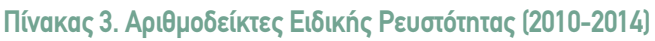

\begin{tabular}{|c|c|c|c|c|c|c|c|}
\hline 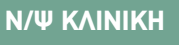 & 2010 & 2011 & 2012 & 2013 & 2014 & м.0. & \% METABOAH \\
\hline K入ıvıkń 1 & 3,42 & 6,64 & 6,14 & 9,13 & 9,69 & 7,00 & $+183,33 \%$ \\
\hline K入ıvıkń 2 & 1,39 & 1,56 & 1,29 & 1,50 & 0,89 & 1,33 & $-35,97 \%$ \\
\hline K入ıvıkń 3 & $M / \Delta$ & 1,00 & 1,10 & 2,07 & 1,46 & 1,41 & $+46,00 \%$ \\
\hline K入ıvıкń 4 & 2,54 & 3,23 & 3,50 & 3,76 & 3,96 & 3,40 & $+55,91 \%$ \\
\hline K入ıvıkń 5 & 1,25 & 1,49 & 1,37 & 1,44 & 0,99 & 1,31 & $-20,80 \%$ \\
\hline M.O. K^A $\triangle O Y$ & 1,42 & 2,06 & 1,77 & 2,08 & 2,14 & 1,89 & $+50,70 \%$ \\
\hline
\end{tabular}

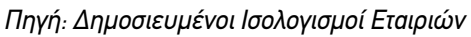

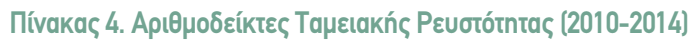

\begin{tabular}{|c|c|c|c|c|c|c|c|}
\hline 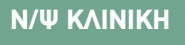 & 2010 & 2011 & 2012 & 2013 & 2014 & м.0. & \% METABONH \\
\hline K入ıııkń 1 & 0,17 & 0,01 & 0,30 & 1,16 & 1,77 & 0,68 & $+941,18 \%$ \\
\hline K入ııเKń 2 & 0,26 & 0,10 & 0,01 & 0,13 & 0,06 & 0,11 & $-76,92 \%$ \\
\hline K入ıvıkń 3 & $M / \Delta$ & 0,13 & 0,07 & 0,32 & 0,24 & 0,19 & $+84,62 \%$ \\
\hline K入ııเкń 4 & 0,74 & 0,68 & 0,19 & 0,70 & 2,10 & 0,88 & $+183,78 \%$ \\
\hline K入ıııкń 5 & 0,10 & 0,18 & 0,04 & 0,14 & 0,10 & 0,11 & $0,00 \%$ \\
\hline M.O. KАA $\Delta O Y$ & 0,33 & 0,25 & 0,11 & 0,27 & 0,32 & 0,26 & $-3,03 \%$ \\
\hline
\end{tabular}

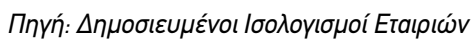

\section{АПОТЕАЕรMATA}

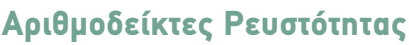

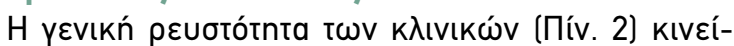

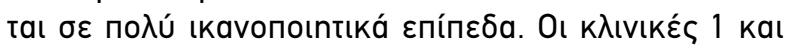

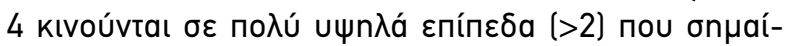

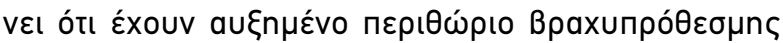

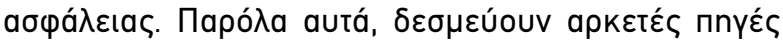

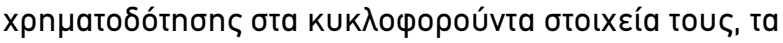

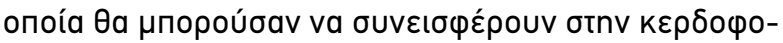

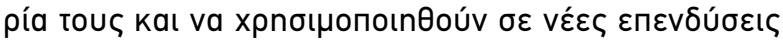

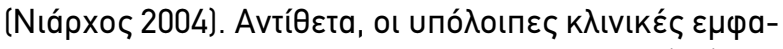

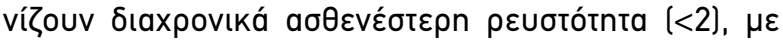

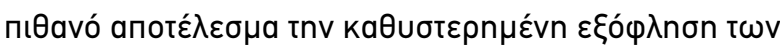

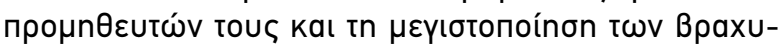

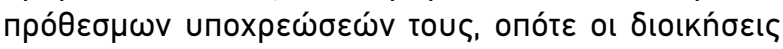

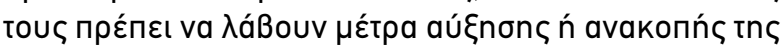

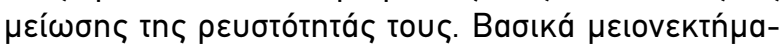

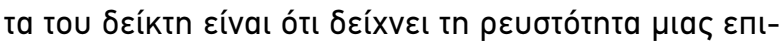

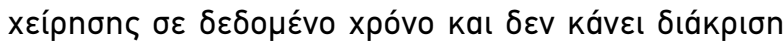

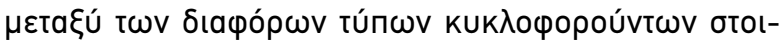

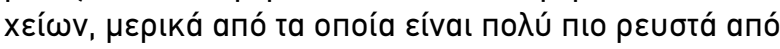

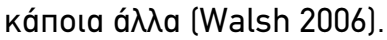

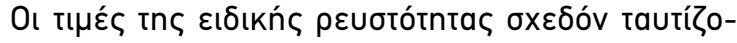

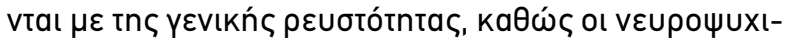




\section{EPEYNHTIKA APOPA}

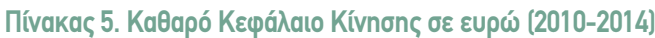

\begin{tabular}{|c|c|c|c|c|c|c|c|}
\hline 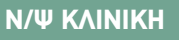 & 2010 & 2011 & 2012 & 2013 & 2014 & м.0. & \% METABONH \\
\hline K入ıvıkń 1 & 5.825 .592 & 14.907 .699 & 12.162 .406 & 11.877 .858 & 11.015 .812 & 11.157 .874 & $+89,09 \%$ \\
\hline K入ıvıkń 2 & 1.080 .260 & 1.392 .547 & 1.189 .130 & 1.590 .779 & -276.156 & 995.312 & $-125,56 \%$ \\
\hline K入ııııń 3 & $M / \Delta$ & 38.457 & 476.931 & 2.134 .938 & 555.751 & 801.519 & $+1345,12 \%$ \\
\hline K入ıvıkń 4 & 3.936 .766 & 5.588 .376 & 6.197 .491 & 4.989 .521 & 2.794 .658 & 4.701 .362 & $-29,01 \%$ \\
\hline K入ıvıкń 5 & 349.959 & 615.965 & 654.279 & 593.989 & -1.502 & 442.538 & $-100,43 \%$ \\
\hline M.O. KАA $\triangle O Y$ & -6.105 .690 & -5.766 .785 & -1.915 .351 & -5.888 .463 & -14.318 .031 & -6.798 .864 & $-148,28 \%$ \\
\hline
\end{tabular}

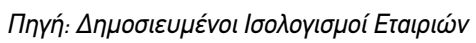

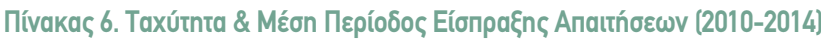

\begin{tabular}{|c|c|c|c|c|c|c|c|c|c|c|c|c|}
\hline 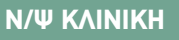 & \multicolumn{2}{|c|}{2010} & \multicolumn{2}{|c|}{2011} & \multicolumn{2}{|c|}{2012} & \multicolumn{2}{|c|}{2013} & \multicolumn{2}{|c|}{2014} & \multirow{2}{*}{$\frac{\text { M.O. }}{\mathrm{Hp}}$} & \multirow{2}{*}{$\begin{array}{c}\% \text { METABOA } \\
\text { Hргрб́V }\end{array}$} \\
\hline & ${ }^{*} \mathbf{A} / \mathbf{\Delta}$ & $* \mathrm{H \mu}$ & $\mathbf{A} / \mathbf{\Delta}$ & $\mathrm{H \mu}$ & $\mathbf{A} / \mathbf{\Delta}$ & $\mathrm{H \mu}$ & $\mathbf{A} / \mathbf{\Delta}$ & $\mathrm{H \mu}$ & $\mathbf{A} \mathbf{\Delta}$ & $\mathrm{H \mu}$ & & \\
\hline K入ıııкń 1 & 1,41 & 260 & 0,56 & 656 & 0,45 & 809 & 0,31 & 1182 & 0,35 & 1052 & 792 & $+304,62 \%$ \\
\hline K入ıvıкń 2 & 1,70 & 214 & 1,38 & 264 & 0,93 & 394 & 0,75 & 488 & 0,50 & 736 & 419 & $+243,93 \%$ \\
\hline K入ıvıкń 3 & $\mathrm{M} / \Delta$ & $M / \Delta$ & 1,38 & 264 & 1,01 & 362 & 0,55 & 668 & 0,99 & 368 & 416 & $+39,39 \%$ \\
\hline K入ıvıкń 4 & 1,72 & 213 & 1,30 & 281 & 0,65 & 558 & 0,26 & 1389 & 0,16 & 2235 & 935 & $+949,30 \%$ \\
\hline K入ıvıkń 5 & 1,96 & 186 & 1,57 & 233 & 1,06 & 343 & 0,78 & 469 & 0,73 & 503 & 347 & $+170,43 \%$ \\
\hline M.O. KАA $\triangle O Y$ & $\mathrm{M} / \Delta$ & 230 & $M / \Delta$ & 241 & $\mathrm{M} / \Delta$ & 343 & $M / \Delta$ & 346 & $\mathrm{M} / \Delta$ & 339 & 300 & $+47,39 \%$ \\
\hline
\end{tabular}

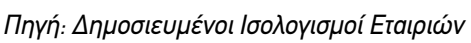

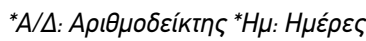

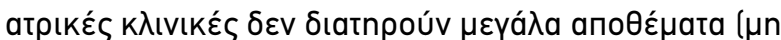

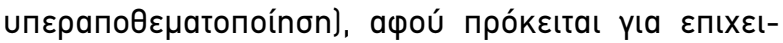

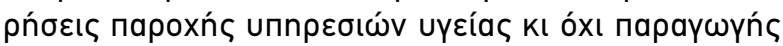

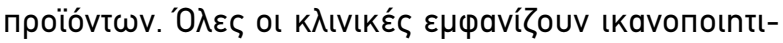

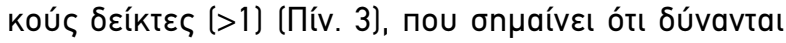

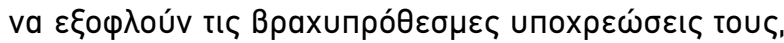

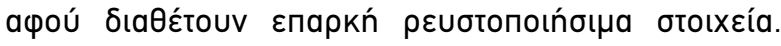

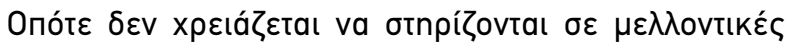

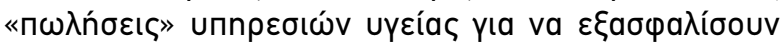

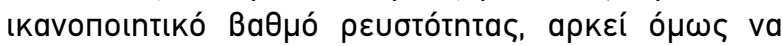

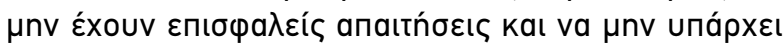

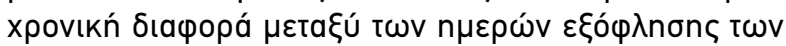

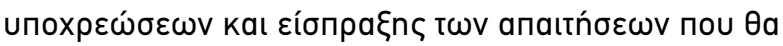

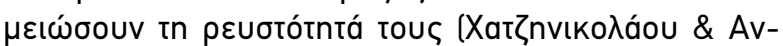

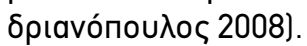

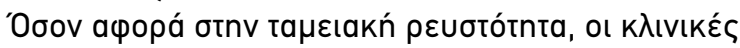

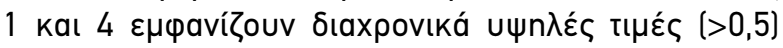

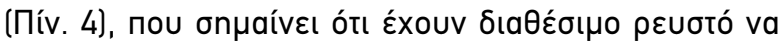

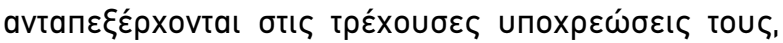

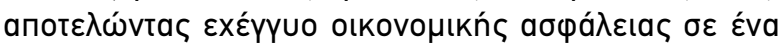

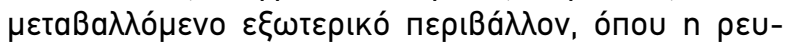

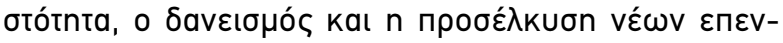

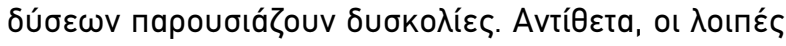

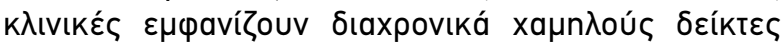

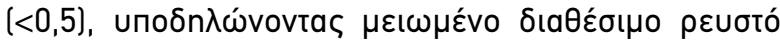

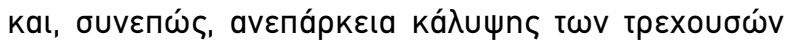

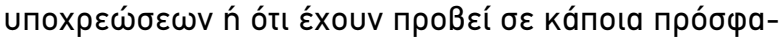
tn $\varepsilon \sqcap \varepsilon ́ v \delta$

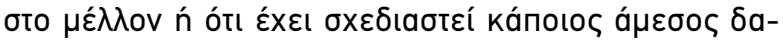

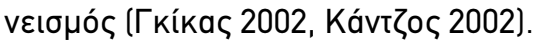

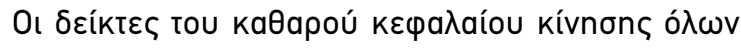

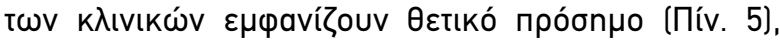

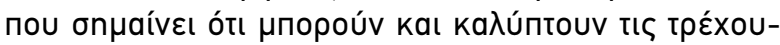

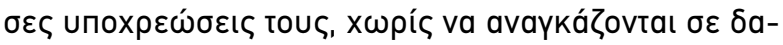

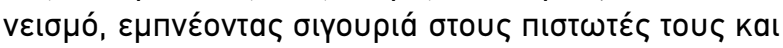

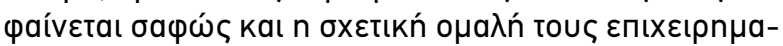

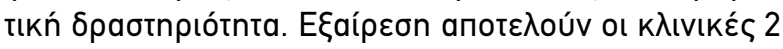

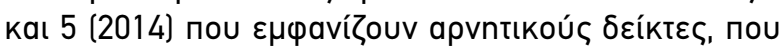

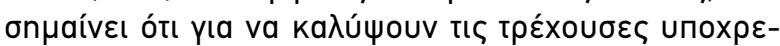

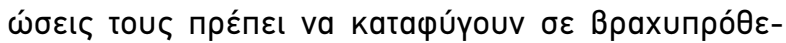

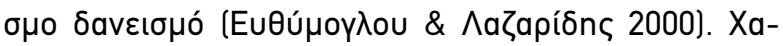

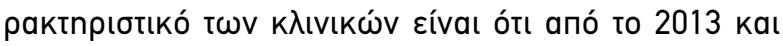

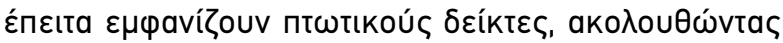

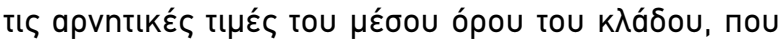

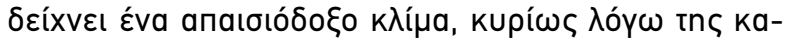

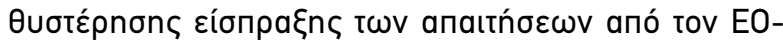

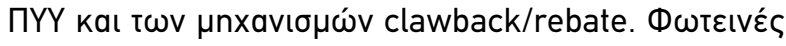

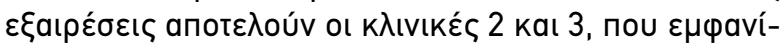




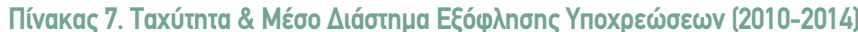

\begin{tabular}{|c|c|c|c|c|c|c|c|c|c|c|c|c|}
\hline \multirow[t]{2}{*}{ 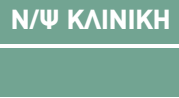 } & \multicolumn{2}{|c|}{2010} & \multicolumn{2}{|c|}{2011} & \multicolumn{2}{|c|}{2012} & \multicolumn{2}{|c|}{2013} & \multicolumn{2}{|c|}{2014} & \multirow{2}{*}{$\frac{\text { M.O. }}{\mathrm{H \mu}}$} & \multirow{2}{*}{\begin{tabular}{|c|}
$\%$ METABONH \\
Hнєрб́v
\end{tabular}} \\
\hline & A $\mathbf{A} \Delta$ & "Hp & $\mathbf{A} / \mathbf{\Delta}$ & Нн & $\mathbf{A} / \mathbf{\Delta}$ & $\mathrm{H \mu}$ & $\mathbf{A} \mathbf{\Delta}$ & $\mathrm{Hp}$ & $\mathbf{A} / \mathbf{\Delta}$ & $\mathrm{H \mu}$ & & \\
\hline K入ıvıkń 1 & 2,54 & 144 & 1,99 & 183 & 1,90 & 192 & 1,90 & 192 & 2,94 & 124 & 167 & $-13,89 \%$ \\
\hline K入ıvıkń 2 & 1,94 & 188 & 1,60 & 228 & 1,07 & 341 & 0,87 & 417 & 1,00 & 364 & 308 & $+93,62 \%$ \\
\hline K入ıvıkń 3 & $M / \Delta$ & $M / \Delta$ & 0,91 & 403 & 0,83 & 441 & 0,94 & 386 & 1,90 & 192 & 356 & $-52,36 \%$ \\
\hline K入ıvıkń 4 & 1,82 & 201 & 1,79 & 204 & 1,55 & 235 & 1,31 & 279 & 1,80 & 203 & 224 & $+1,00 \%$ \\
\hline K入ıvıkń 5 & 1,88 & 194 & 1,68 & 217 & 1,27 & 288 & 1,02 & 357 & 1,10 & 331 & 277 & $+70,62 \%$ \\
\hline M.O. KАA $\Delta O Y$ & $M / \Delta$ & 180 & $M / \Delta$ & 177 & $M / \Delta$ & 206 & $M / \Delta$ & 203 & $M / \Delta$ & 167 & 187 & $-7,22 \%$ \\
\hline
\end{tabular}

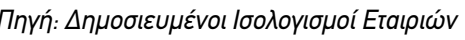

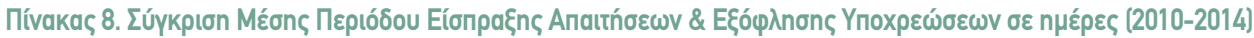

\begin{tabular}{|c|c|c|c|c|c|c|c|c|c|c|}
\hline \multirow[t]{2}{*}{ N/W KAINIKH } & \multicolumn{2}{|c|}{2010} & \multicolumn{2}{|c|}{2011} & \multicolumn{2}{|c|}{2012} & \multicolumn{2}{|c|}{2013} & \multicolumn{2}{|c|}{2014} \\
\hline & "MПEA & $* M \Delta E Y$ & MПEA & MAEY & MחEA & MAEY & MПEA & MAEY & MחEA & MAEY \\
\hline K入ıııkń 1 & 260 & 144 & 656 & 183 & 809 & 192 & 1182 & 192 & 1052 & 124 \\
\hline K入ıvıкń 2 & 214 & 188 & 264 & 228 & 394 & 341 & 488 & 417 & 736 & 364 \\
\hline K入ıvııń 3 & $M / \Delta$ & $M / \Delta$ & 264 & 403 & 362 & 441 & 668 & 386 & 368 & 192 \\
\hline K入ıvıkń 4 & 213 & 201 & 281 & 204 & 558 & 235 & 1389 & 279 & 2235 & 203 \\
\hline K入ıvıкń 5 & 186 & 194 & 233 & 217 & 343 & 288 & 469 & 357 & 503 & 331 \\
\hline M.O. K^A $\triangle O Y$ & 230 & 180 & 241 & 177 & 343 & 206 & 346 & 203 & 339 & 167 \\
\hline
\end{tabular}

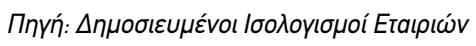

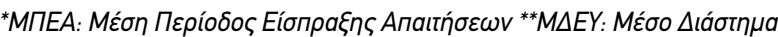

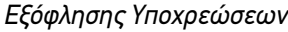

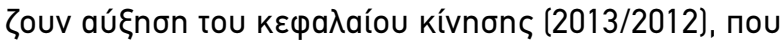

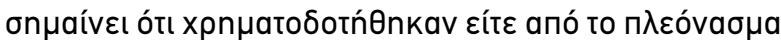

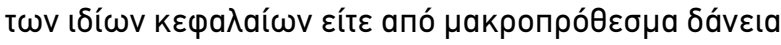

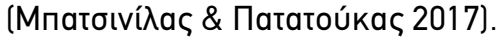

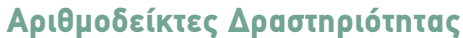

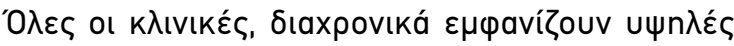

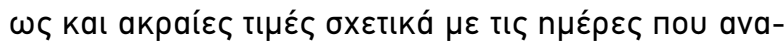

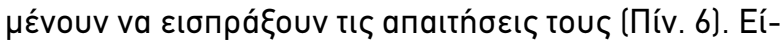

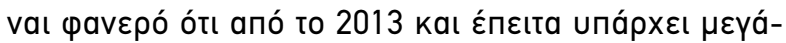

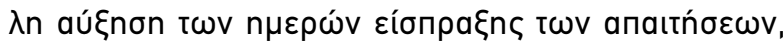

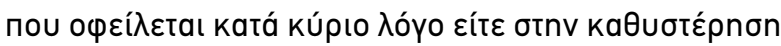

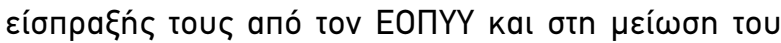

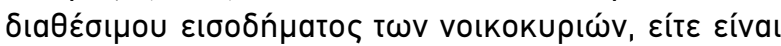

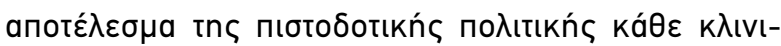

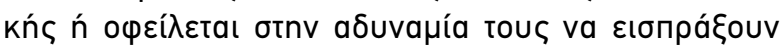

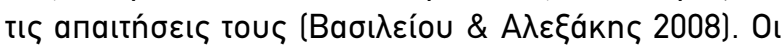

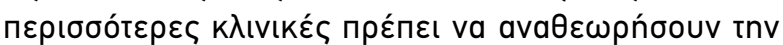

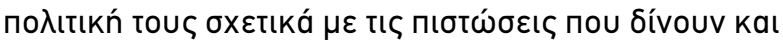

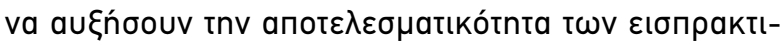

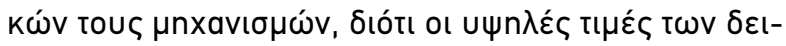

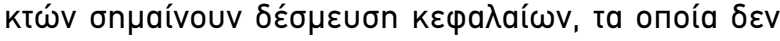

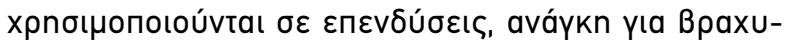

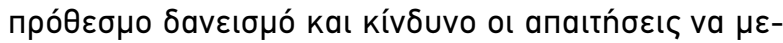

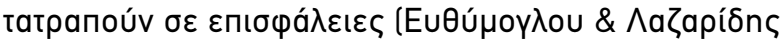
2000).

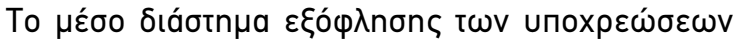

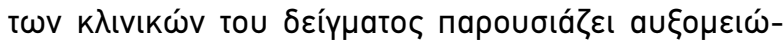

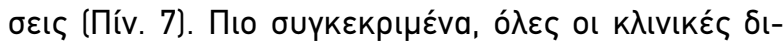

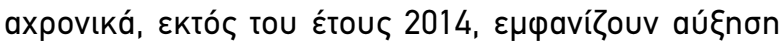

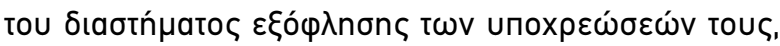

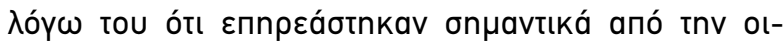

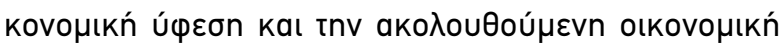

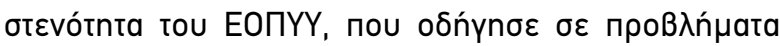

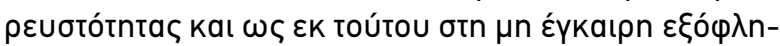

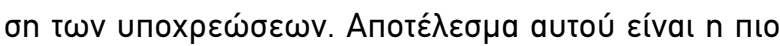

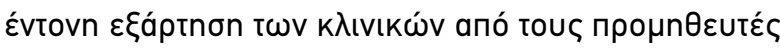

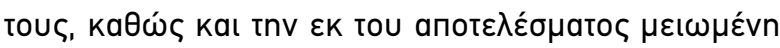

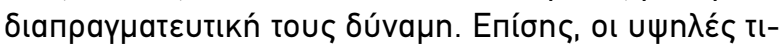

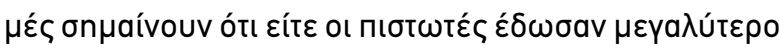

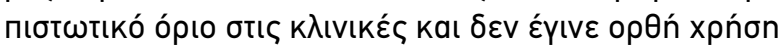

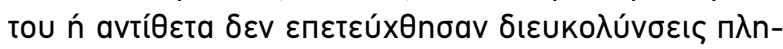




\section{EPEYNHTIKA APOPA}

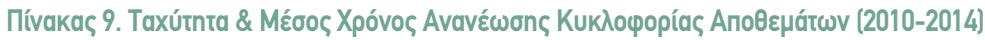

\begin{tabular}{|c|c|c|c|c|c|c|c|c|c|c|c|c|}
\hline 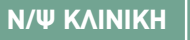 & \multicolumn{2}{|c|}{2010} & \multicolumn{2}{|c|}{2011} & \multicolumn{2}{|c|}{2012} & \multicolumn{2}{|c|}{2013} & \multicolumn{2}{|c|}{2014} & \multirow{2}{*}{$\frac{\text { M.O. }}{\mathrm{H \mu}}$} & \multirow{2}{*}{$\begin{array}{c}\text { \% METABOAH } \\
\text { Нрврб์V }\end{array}$} \\
\hline & *A/ $\mathbf{\Delta}$ & ${ }^{* *} \mathrm{H} \mu$ & $\mathbf{A} \mathbf{\Delta}$ & Hр & $\mathbf{A} / \mathbf{\Delta}$ & $\mathrm{H \mu}$ & $\mathbf{A} \mathbf{\Delta}$ & $\mathrm{H \mu}$ & $\mathbf{A} / \mathbf{\Delta}$ & Нp & & \\
\hline K入ıııкń 1 & 480,97 & 1 & 233,69 & 2 & 196,45 & 2 & 107,25 & 3 & 114,98 & 3 & 2 & $+200,00 \%$ \\
\hline K入ıııкń 2 & 140,91 & 3 & 135,11 & 3 & 111,90 & 3 & 102,83 & 4 & 129,51 & 3 & 3 & $+0,00 \%$ \\
\hline K入ıvıkń 3 & $M / \Delta$ & $M / \Delta$ & 70,30 & 5 & 73,62 & 5 & 56,32 & 6 & 56,61 & 6 & 6 & $+20,00 \%$ \\
\hline K入ıııkń 4 & 52,65 & 7 & 46,93 & 8 & 45,84 & 8 & 44,96 & 8 & 41,26 & 9 & 8 & $+28,57 \%$ \\
\hline K入ıเvıкń 5 & 82,35 & 4 & 111,37 & 3 & 123,69 & 3 & 124,17 & 3 & 102,25 & 4 & 3 & $0,00 \%$ \\
\hline M.O. KAINIKSN & $M / \Delta$ & 4 & $\mathrm{M} / \Delta$ & 4 & $M / \Delta$ & 4 & $\mathrm{M} / \Delta$ & 5 & $\mathrm{M} / \Delta$ & 6 & 5 & $+50,00 \%$ \\
\hline
\end{tabular}

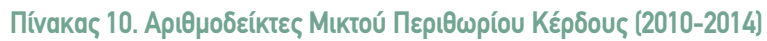

\begin{tabular}{|c|c|c|c|c|c|c|c|}
\hline 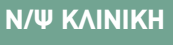 & 2010 & 2011 & 2012 & 2013 & 2014 & м.0. & \% METABONH \\
\hline K入ıvıкń 1 & $38,94 \%$ & $43,02 \%$ & $32,75 \%$ & $7,28 \%$ & $-0,21 \%$ & $24,36 \%$ & $-100,54 \%$ \\
\hline K入ıvıkń 2 & $14,01 \%$ & $12,62 \%$ & $16,18 \%$ & $13,33 \%$ & $-76,49 \%$ & $-4,07 \%$ & $-645,97 \%$ \\
\hline Kגıvıkń 3 & $M / \Delta$ & $24,49 \%$ & $14,72 \%$ & $-4,89 \%$ & $-50,51 \%$ & $-4,05 \%$ & $-306,25 \%$ \\
\hline K入ıııкń 4 & $31,93 \%$ & $34,30 \%$ & $18,49 \%$ & $-55,28 \%$ & $-313,67 \%$ & $-56,85 \%$ & $-1082,37 \%$ \\
\hline K入ıvıкń 5 & $20,59 \%$ & $16,74 \%$ & $16,48 \%$ & $7,28 \%$ & $-27,72 \%$ & $6,67 \%$ & $-234,63 \%$ \\
\hline M.O. K^A $\triangle O Y$ & $14,88 \%$ & $12,44 \%$ & $25,59 \%$ & $13,36 \%$ & $0,97 \%$ & $13,45 \%$ & $-93,48 \%$ \\
\hline
\end{tabular}

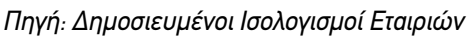

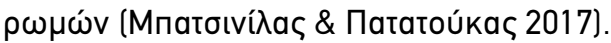

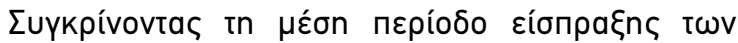

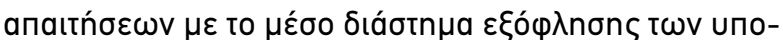

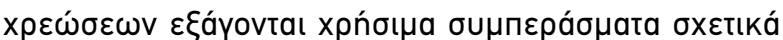

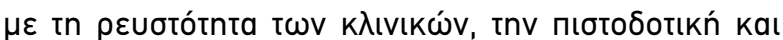

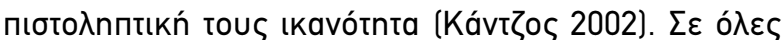

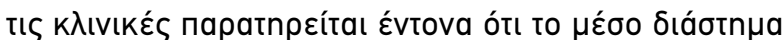

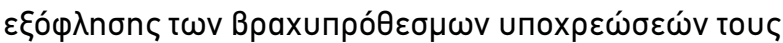

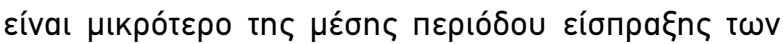

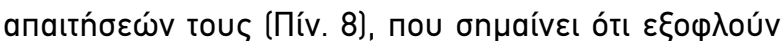

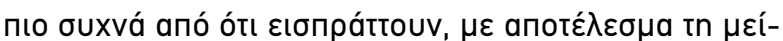

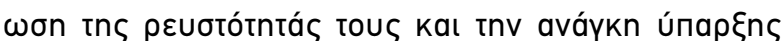

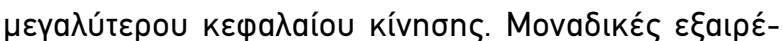

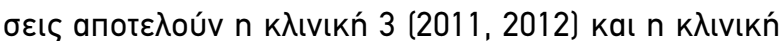

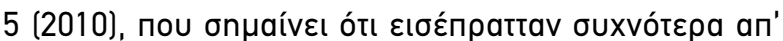

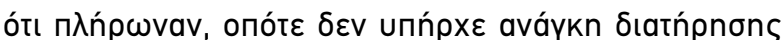

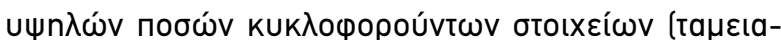

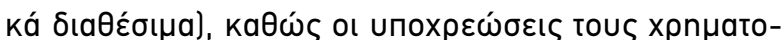

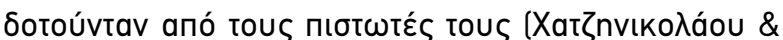

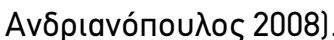

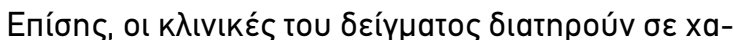

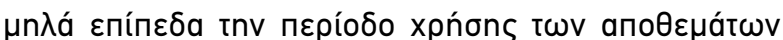

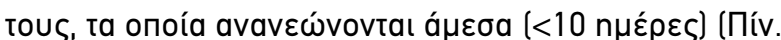

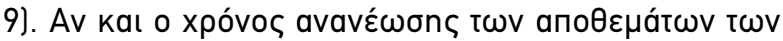

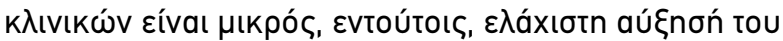

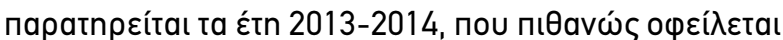

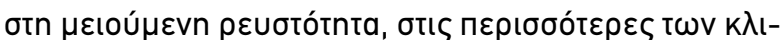

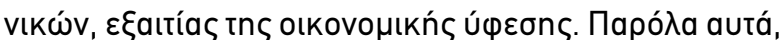

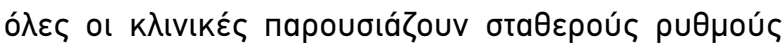

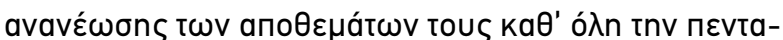

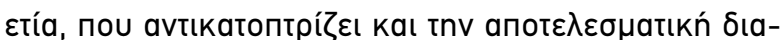

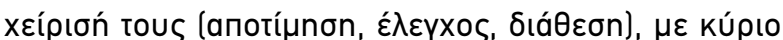

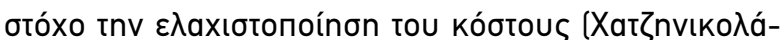

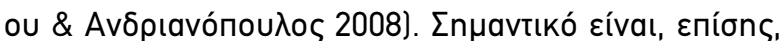

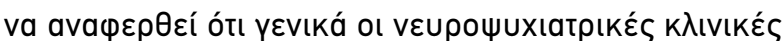

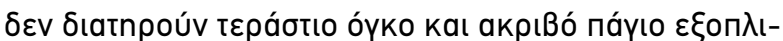

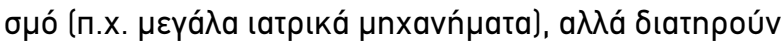

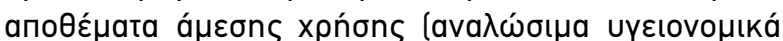

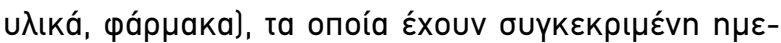

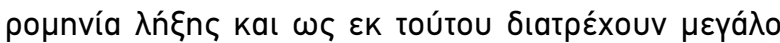

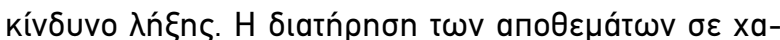

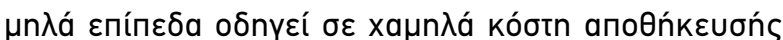

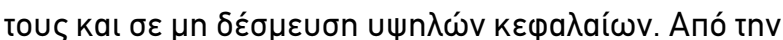

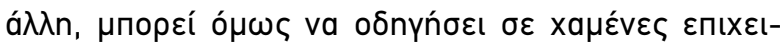

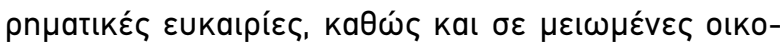

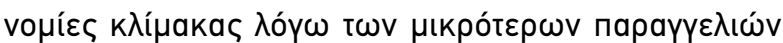

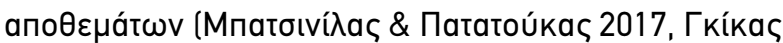
2002). 


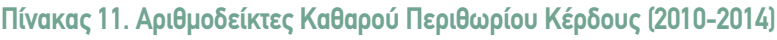

\begin{tabular}{|c|c|c|c|c|c|c|c|}
\hline 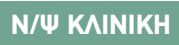 & 2010 & 2011 & 2012 & 2013 & 2014 & M.o. & \% METABOAH \\
\hline K入ııııń 1 & $35,39 \%$ & $38,86 \%$ & $30,58 \%$ & $0,21 \%$ & $-10,00 \%$ & $19,01 \%$ & $-128,26 \%$ \\
\hline K入ıııkń 2 & $4,09 \%$ & $9,07 \%$ & $5,18 \%$ & $1,85 \%$ & $-105,41 \%$ & $-17,04 \%$ & $-2677,26 \%$ \\
\hline K入ıııkń 3 & $M / \Delta$ & $21,18 \%$ & $3,06 \%$ & $-59,36 \%$ & $-67,88 \%$ & $-25,75 \%$ & $-420,49 \%$ \\
\hline K入ıvı́kń 4 & $27,95 \%$ & $30,74 \%$ & $13,27 \%$ & $-72,74 \%$ & $-382,90 \%$ & $-76,74 \%$ & $-1469,95 \%$ \\
\hline K入ıvıkń 5 & $13,67 \%$ & $12,60 \%$ & $5,05 \%$ & $2,92 \%$ & $-35,25 \%$ & $-0,20 \%$ & $-357,86 \%$ \\
\hline M.O. KАA $\triangle O Y$ & $-11,13 \%$ & $-16,08 \%$ & $3,80 \%$ & $-12,19 \%$ & $-32,84 \%$ & $-13,69 \%$ & $-23,00 \%$ \\
\hline
\end{tabular}

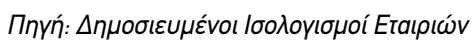

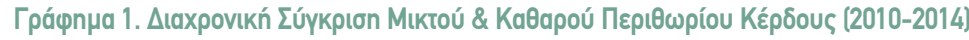

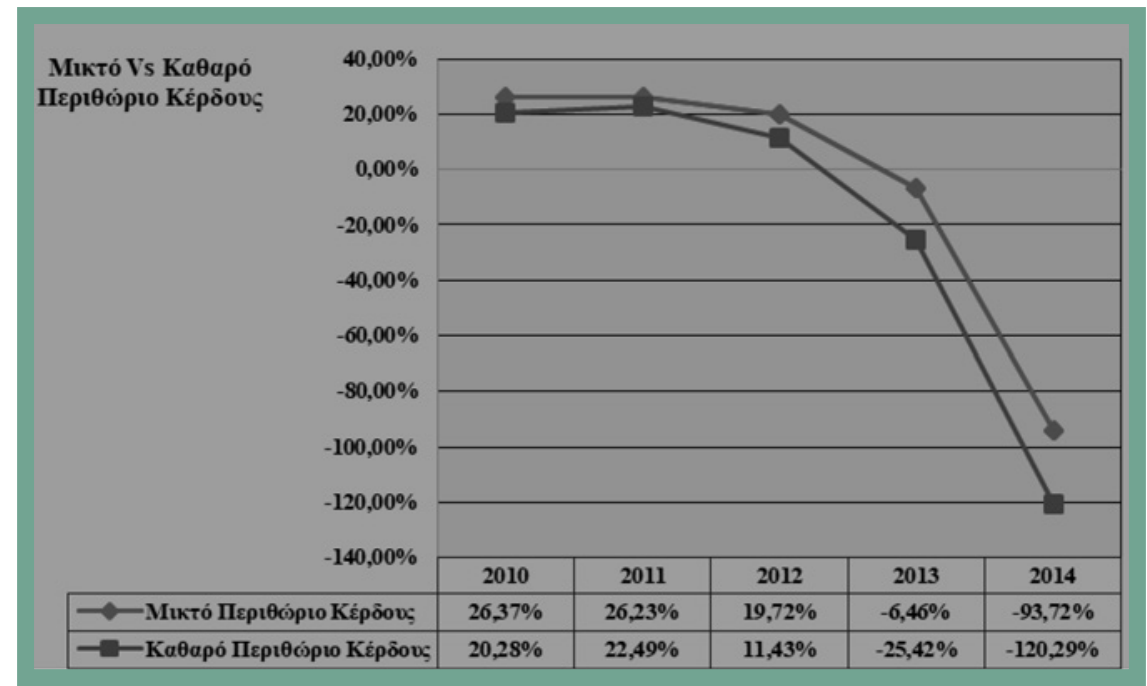

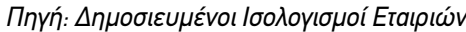

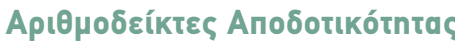

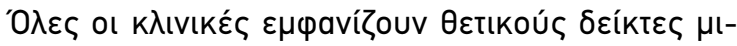

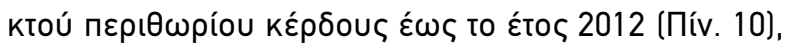

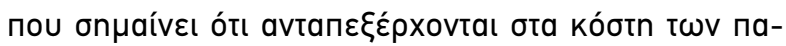

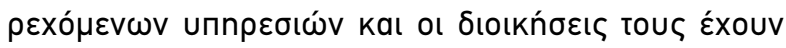

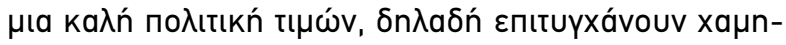

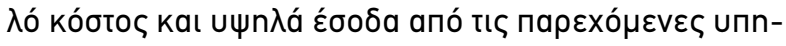

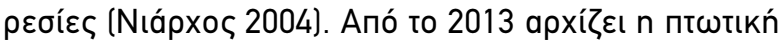

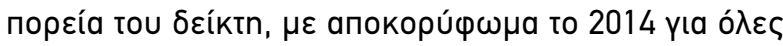

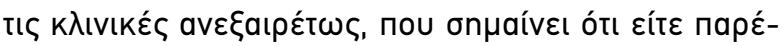

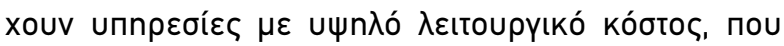

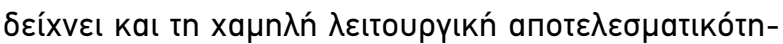

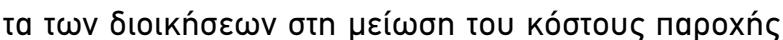

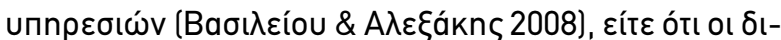

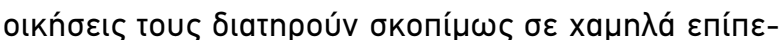

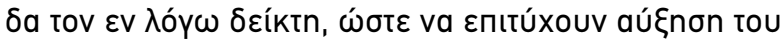

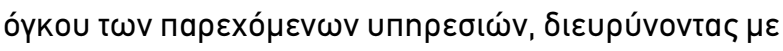

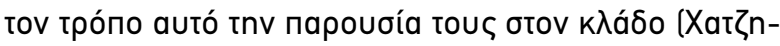

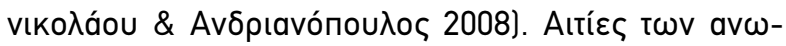

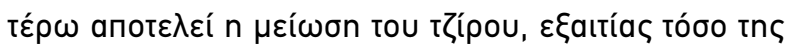

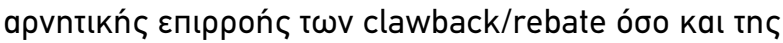

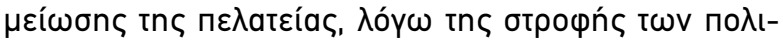

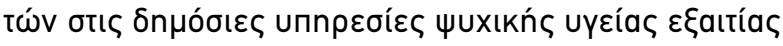

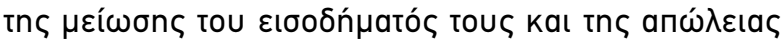

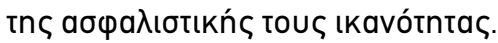

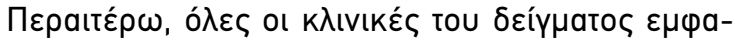

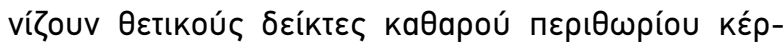

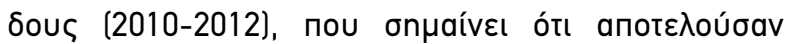

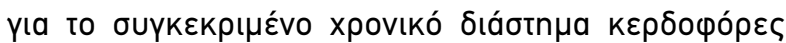

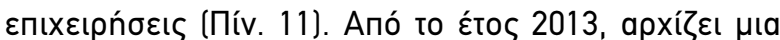

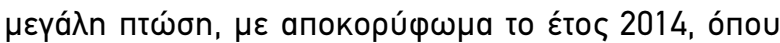

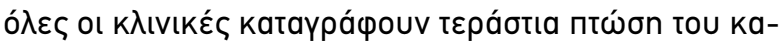




\section{EPEYNHTIKA APOPA}

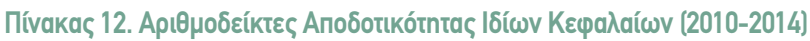

\begin{tabular}{|c|c|c|c|c|c|c|c|}
\hline 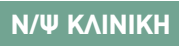 & 2010 & 2011 & 2012 & 2013 & 2014 & M.O. & \% METABONH \\
\hline K入ıvıkń 1 & $32,80 \%$ & $26,49 \%$ & $12,39 \%$ & $0,05 \%$ & $-2,20 \%$ & $13,91 \%$ & $-106,71 \%$ \\
\hline K入ıııเKń 2 & $11,14 \%$ & $20,02 \%$ & $8,83 \%$ & $2,74 \%$ & $-257,98 \%$ & $-43,05 \%$ & $-2415,80 \%$ \\
\hline K入ıvııń 3 & $M / \Delta$ & $32,04 \%$ & $3,79 \%$ & $-79,57 \%$ & $-180,96 \%$ & $-56,18 \%$ & $-664,79 \%$ \\
\hline K入ıııเKń 4 & $32,61 \%$ & $27,98 \%$ & $7,85 \%$ & $-19,67 \%$ & $-51,77 \%$ & $-0,60 \%$ & $-258,75 \%$ \\
\hline K入ıvııń 5 & $85,37 \%$ & $47,71 \%$ & $14,31 \%$ & $6,05 \%$ & $-102,47 \%$ & $10,19 \%$ & $-220,03 \%$ \\
\hline M.O. KАA $\Delta O Y$ & $0,62 \%$ & $-3,80 \%$ & $22,09 \%$ & $-19,76 \%$ & $-32,46 \%$ & $-6,66 \%$ & $-1174,19 \%$ \\
\hline
\end{tabular}

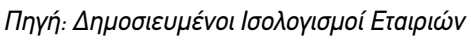

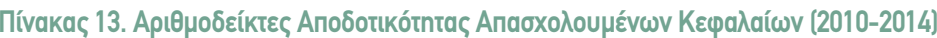

\begin{tabular}{|c|c|c|c|c|c|c|c|}
\hline 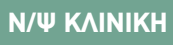 & 2010 & 2011 & 2012 & 2013 & 2014 & м.0. & \% METABONH \\
\hline K入ıııкń 1 & $18,65 \%$ & $17,05 \%$ & $9,17 \%$ & $0,04 \%$ & $-1,76 \%$ & $8,63 \%$ & $-109,44 \%$ \\
\hline K入ıııเKń 2 & $3,90 \%$ & $8,24 \%$ & $3,21 \%$ & $1,09 \%$ & $-46,39 \%$ & $-5,99 \%$ & $-1289,49 \%$ \\
\hline Kגıvıkń 3 & $M / \Delta$ & $14,15 \%$ & $1,57 \%$ & $-21,78 \%$ & $-49,92 \%$ & $-14,00 \%$ & $-452,79 \%$ \\
\hline K入ıvııń 4 & $22,21 \%$ & $20,70 \%$ & $5,93 \%$ & $-15,41 \%$ & $-42,69 \%$ & $-1,85 \%$ & $-292,21 \%$ \\
\hline K入ıเvıkń 5 & $12,12 \%$ & $10,54 \%$ & $3,18 \%$ & $1,64 \%$ & $-17,07 \%$ & $2,08 \%$ & $-240,84 \%$ \\
\hline M.O. KАA $\triangle O Y$ & $2,89 \%$ & $2,87 \%$ & $5,94 \%$ & $-2,01 \%$ & $-9,91 \%$ & $-0,04 \%$ & $-442,91 \%$ \\
\hline
\end{tabular}

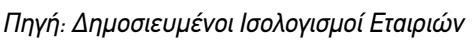

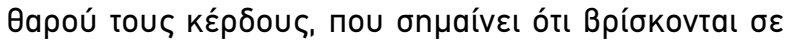

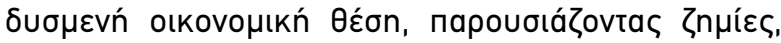

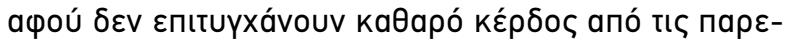

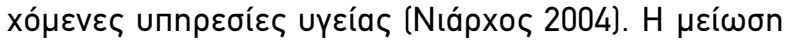

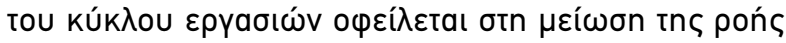

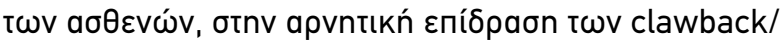

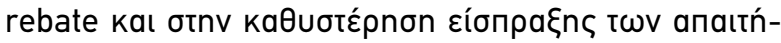

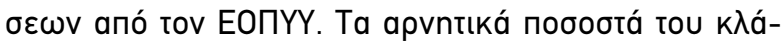

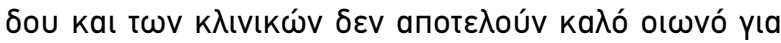

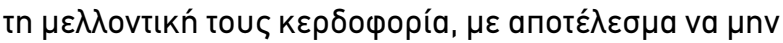

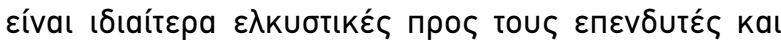

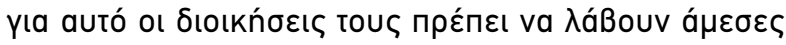

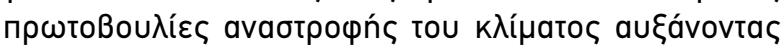

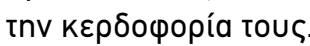

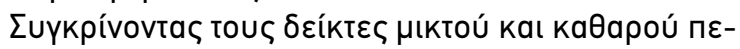

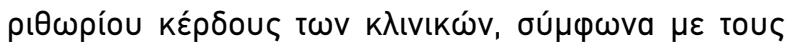

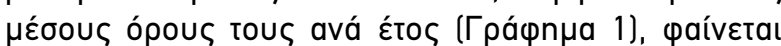

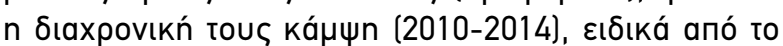

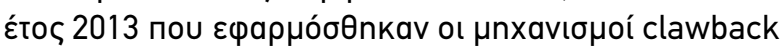

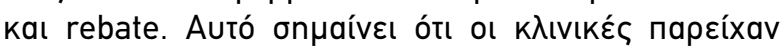

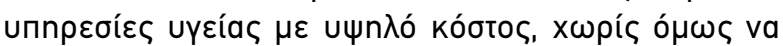

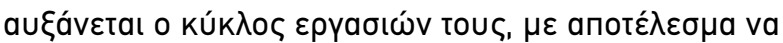

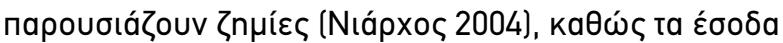

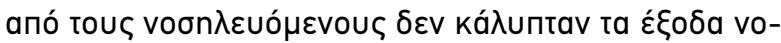

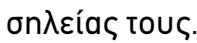

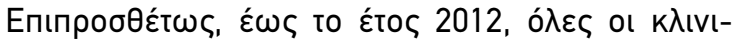

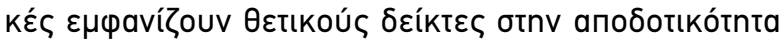
$\tau \omega v$ ıoí

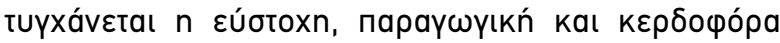

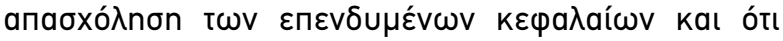

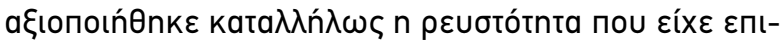

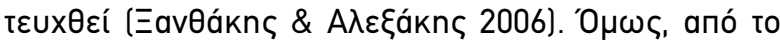

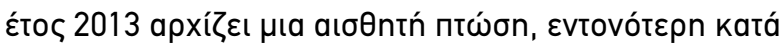

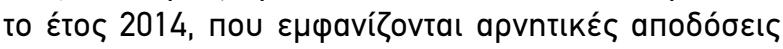

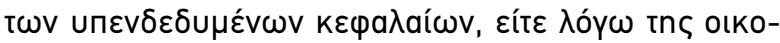

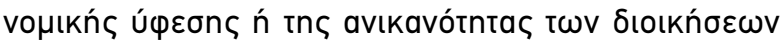

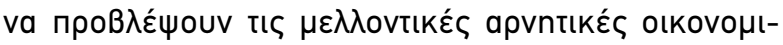

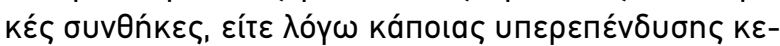

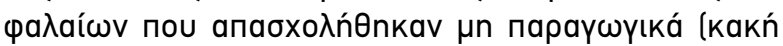

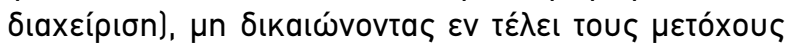
(Nıápxos 2004).

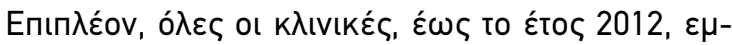

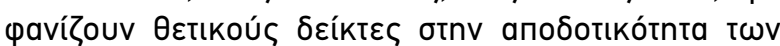

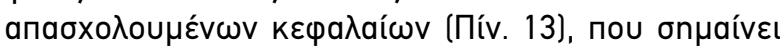

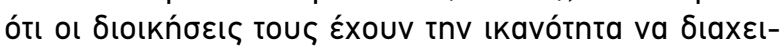

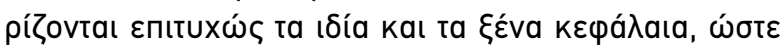

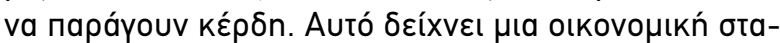

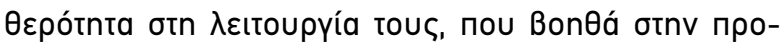

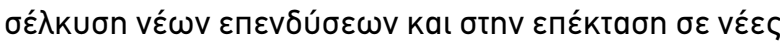

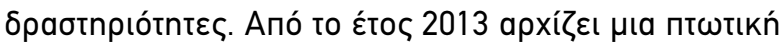




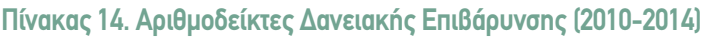

\begin{tabular}{|c|c|c|c|c|c|c|c|}
\hline 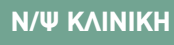 & 2010 & 2011 & 2012 & 2013 & 2014 & M.0. & \% METABONH \\
\hline K入ıııкKń 1 & 0,76 & 0,55 & 0,35 & 0,28 & 0,25 & 0,44 & $-67,11 \%$ \\
\hline K入ıvııń 2 & 1,86 & 1,43 & 1,75 & 1,51 & 4,56 & 2,22 & $+145,16 \%$ \\
\hline K入ıııкর́́ 3 & $M / \Delta$ & 1,26 & 1,42 & 2,65 & 2,62 & 1,99 & $+107,94 \%$ \\
\hline K入ıııเKń 4 & 0,47 & 0,35 & 0,32 & 0,28 & 0,21 & 0,33 & $-55,32 \%$ \\
\hline K入ıvııń 5 & 6,04 & 3,53 & 3,50 & 2,69 & 5,00 & 4,15 & $-17,22 \%$ \\
\hline M.O. KАA $\Delta O Y$ & 4,75 & 5,97 & 2,78 & 3,97 & 3,49 & 4,19 & $-26,53 \%$ \\
\hline
\end{tabular}

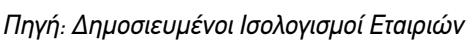

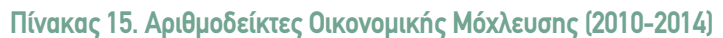

\begin{tabular}{|c|c|c|c|c|c|c|c|}
\hline 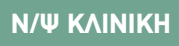 & 2010 & 2011 & 2012 & 2013 & 2014 & M.0. & \% METABOAH \\
\hline K入ıııkń 1 & 1,55 & 1,64 & 1,44 & 1,32 & 1,27 & 1,44 & $-18,06 \%$ \\
\hline K入ıvıkń 2 & 2,60 & 2,63 & 2,60 & 2,63 & 3,17 & 2,73 & $+21,92 \%$ \\
\hline K入ıvıкń 3 & $M / \Delta$ & 2,26 & 2,35 & 2,86 & 3,64 & 2,78 & $+61,06 \%$ \\
\hline K入ıııкń 4 & 1,52 & 1,40 & 1,34 & 1,30 & 1,25 & 1,36 & $-17,76 \%$ \\
\hline K入ıvııń 5 & 6,89 & 5,49 & 4,51 & 4,09 & 4,45 & 5,09 & $-35,41 \%$ \\
\hline M.O. K^A $\triangle O Y$ & 2,38 & 2,26 & 2,07 & 2,04 & $M / \Delta$ & 2,19 & $-14,29 \%$ \\
\hline
\end{tabular}

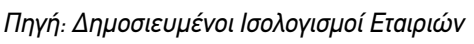

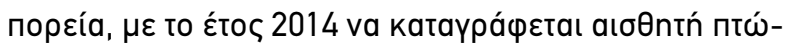

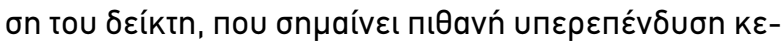

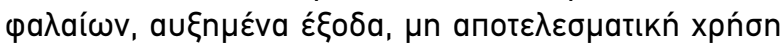

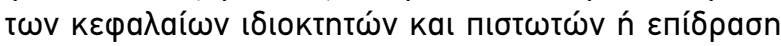

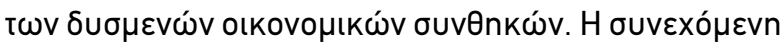

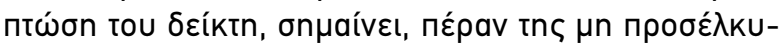

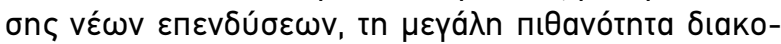

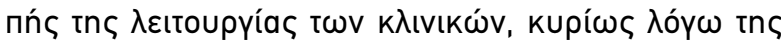

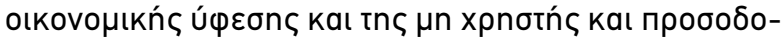

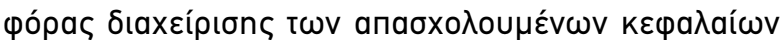

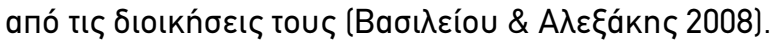

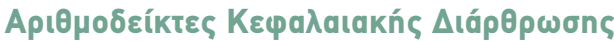

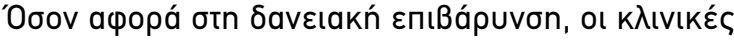

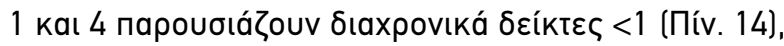

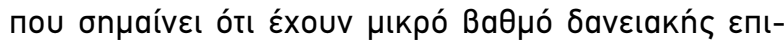

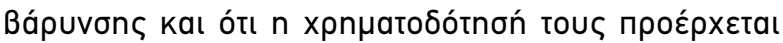

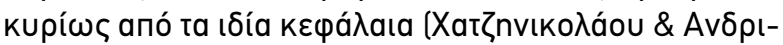

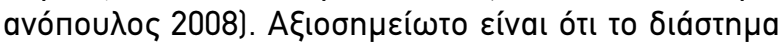

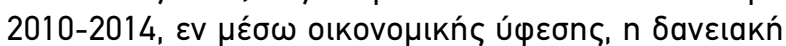

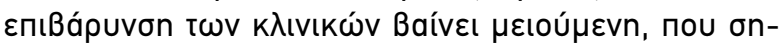

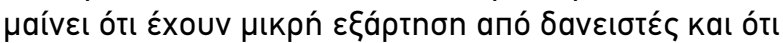

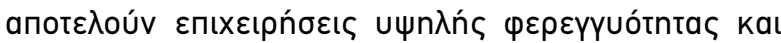

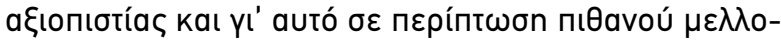

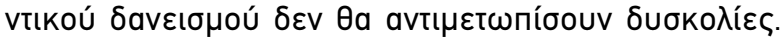

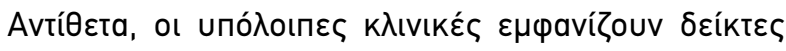

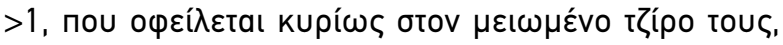

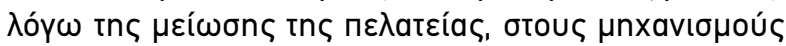

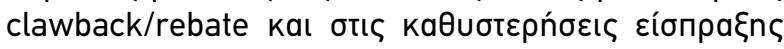

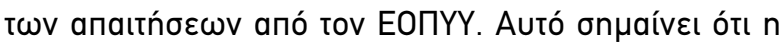

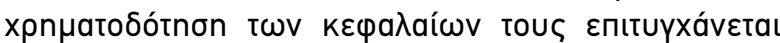

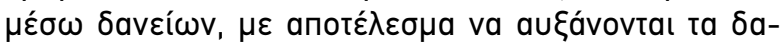

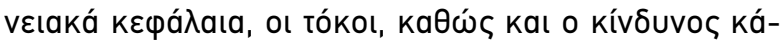

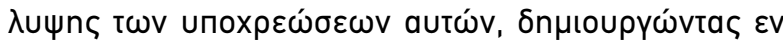

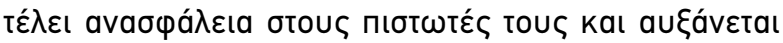

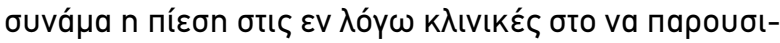

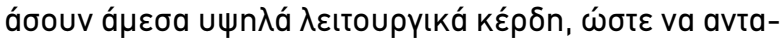

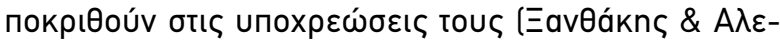

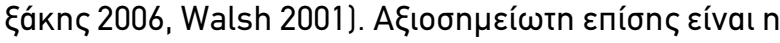

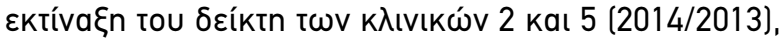

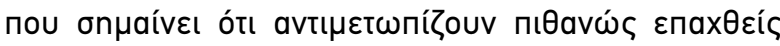

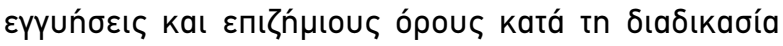

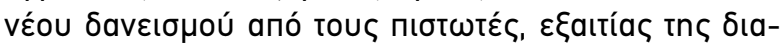

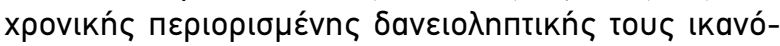

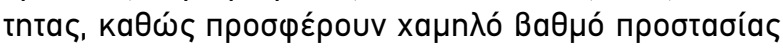

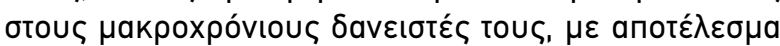

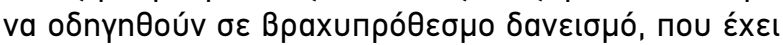

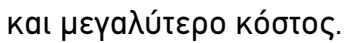

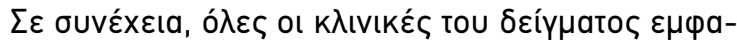

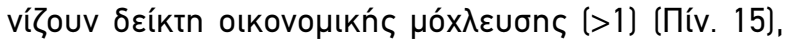




\section{EPEYNHTIKA APOPA}

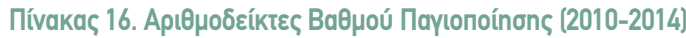

\begin{tabular}{|c|c|c|c|c|c|c|c|}
\hline 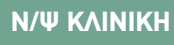 & 2010 & 2011 & 2012 & 2013 & 2014 & M.o. & \% METABONH \\
\hline K入ıııкKń 1 & $52,44 \%$ & $12,62 \%$ & $38,29 \%$ & $40,04 \%$ & $42,32 \%$ & $37,14 \%$ & $-19,30 \%$ \\
\hline K入ıııเKń 2 & $25,44 \%$ & $23,80 \%$ & $19,96 \%$ & $21,20 \%$ & $33,44 \%$ & $24,77 \%$ & $+31,45 \%$ \\
\hline K入ıııкর́́ 3 & $M / \Delta$ & $43,37 \%$ & $34,61 \%$ & $31,86 \%$ & $50,69 \%$ & $40,13 \%$ & $+16,88 \%$ \\
\hline K入ıııเKń 4 & $23,98 \%$ & $19,62 \%$ & $17,18 \%$ & $19,47 \%$ & $29,42 \%$ & $21,93 \%$ & $+22,69 \%$ \\
\hline K入ıvııń 5 & $38,53 \%$ & $34,18 \%$ & $28,13 \%$ & $31,48 \%$ & $37,53 \%$ & $33,97 \%$ & $-2,60 \%$ \\
\hline M.O. KАA $\Delta O Y$ & $47,82 \%$ & $46,03 \%$ & $39,69 \%$ & $42,63 \%$ & $48,08 \%$ & $44,85 \%$ & $+0,54 \%$ \\
\hline
\end{tabular}

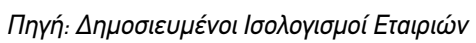

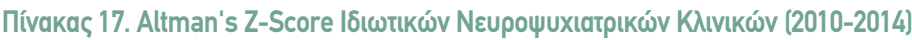

\begin{tabular}{|c|c|c|c|c|c|c|c|}
\hline 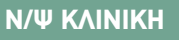 & 2010 & 2011 & 2012 & 2013 & 2014 & M.O. & \% METABONH \\
\hline K入ıvıкń 1 & 4,98 & 7,91 & 6,01 & 5,64 & 5,44 & 6,00 & $9,24 \%$ \\
\hline K入ıเvıkń 2 & 1,94 & 2,50 & 1,77 & 2,34 & $-0,89$ & 1,53 & $-145,88 \%$ \\
\hline K入ıvıkń 3 & $M / \Delta$ & 2,39 & 1,87 & 2,35 & $-1,13$ & 1,37 & $-147,28 \%$ \\
\hline K入ıvıкń 4 & 6,15 & 7,08 & 6,45 & 4,88 & 2,11 & 5,33 & $-65,69 \%$ \\
\hline K入ıเvıкń 5 & 2,03 & 2,89 & 2,36 & 2,32 & $-0,71$ & 1,78 & $-134,98 \%$ \\
\hline
\end{tabular}

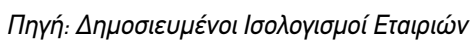

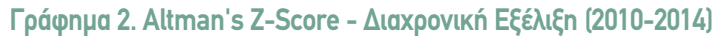

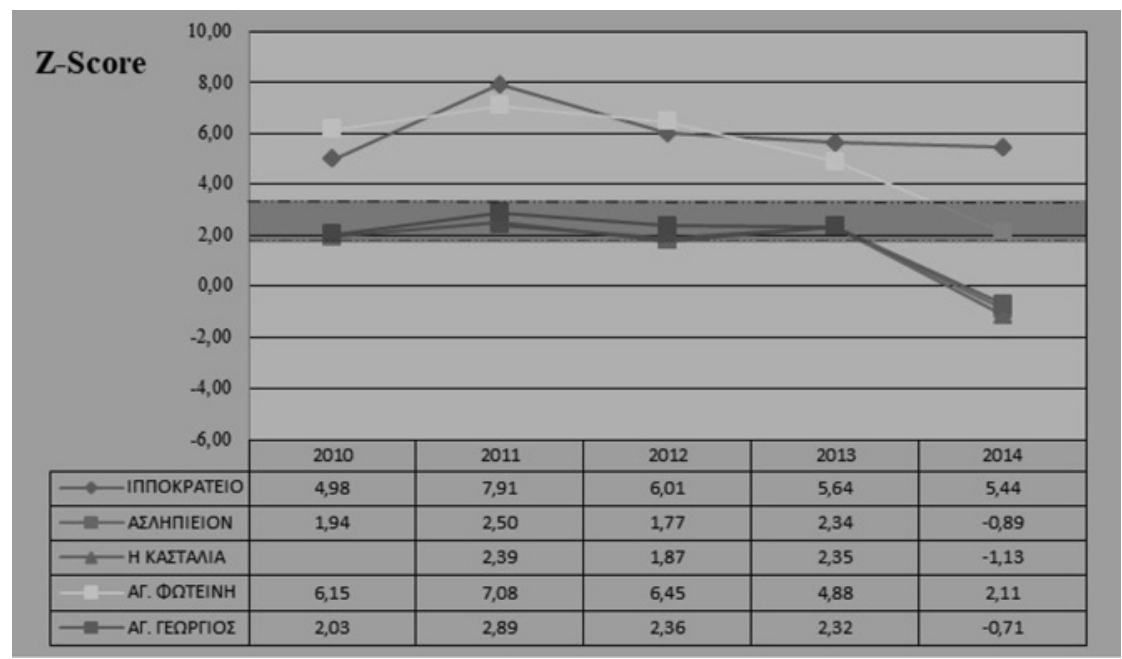

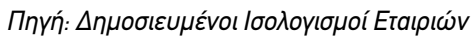




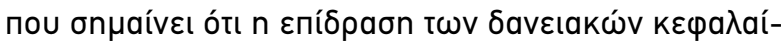

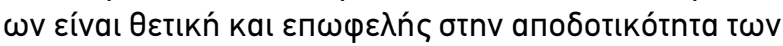

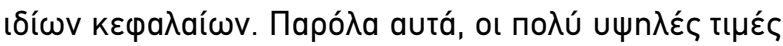

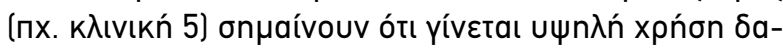

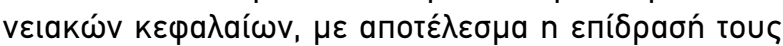

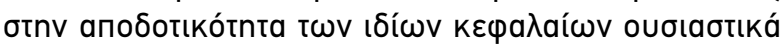

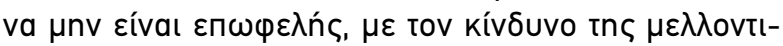

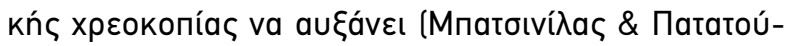
kas 2017, Г kíkas 2002).

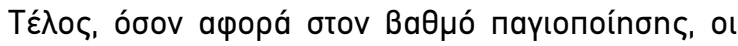

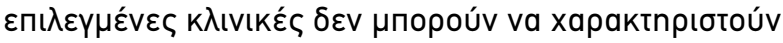
$\omega \varsigma$ olkovo

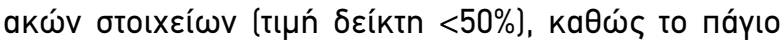

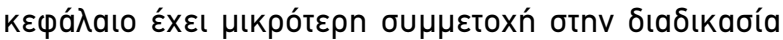
парохń

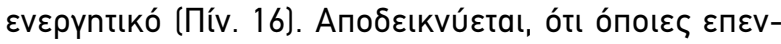

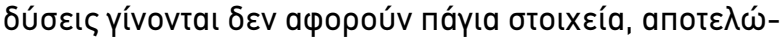

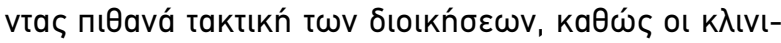

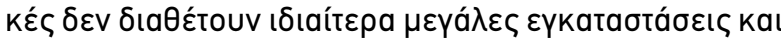

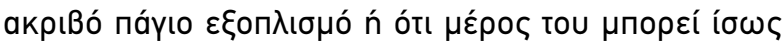

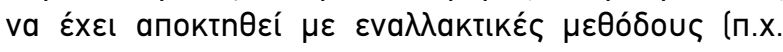

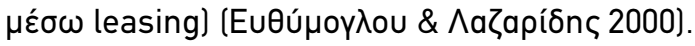

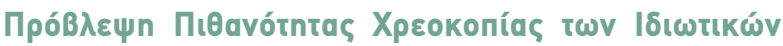

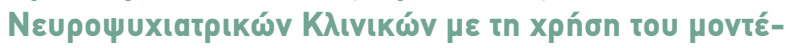

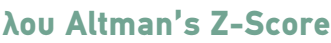

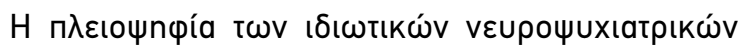

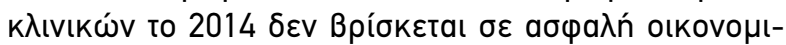

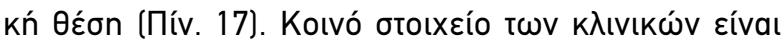

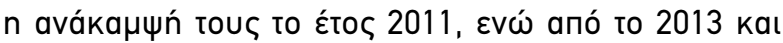

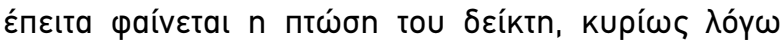

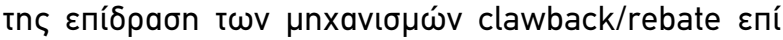

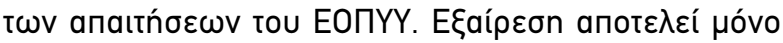

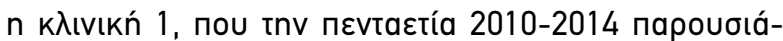

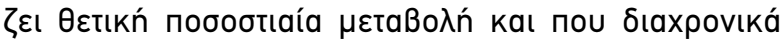

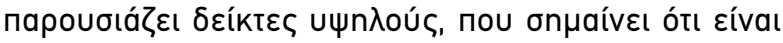

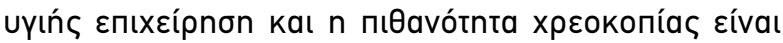

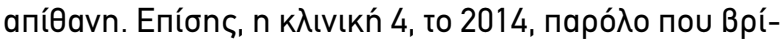

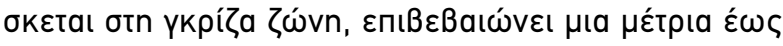

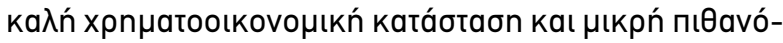

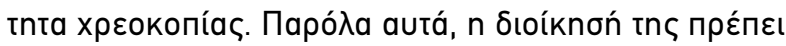

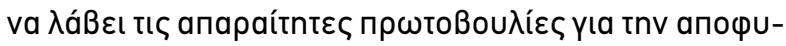

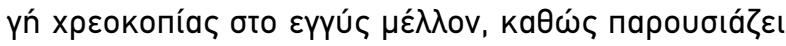

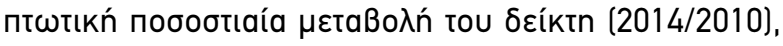

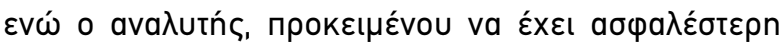

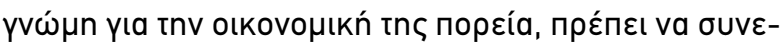

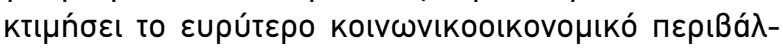

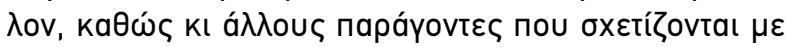

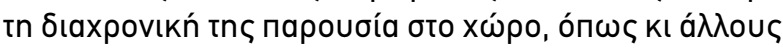

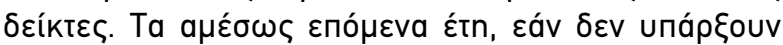

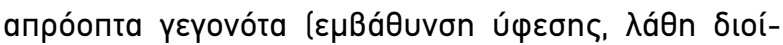

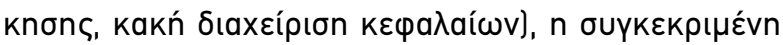

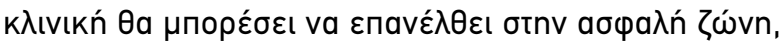

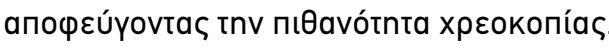

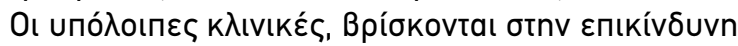

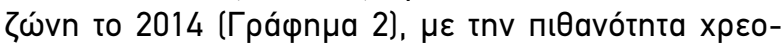

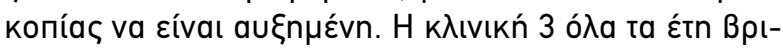

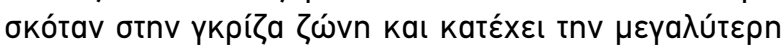

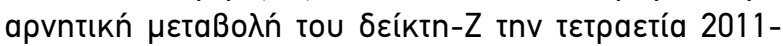

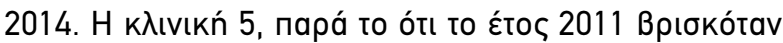

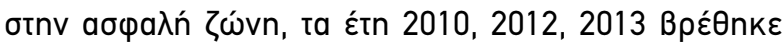

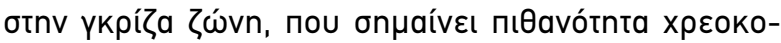

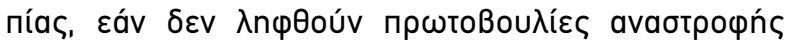

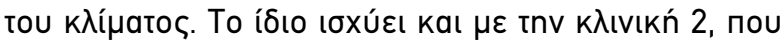

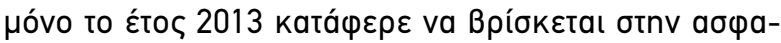

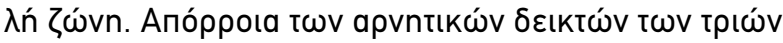

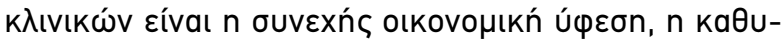

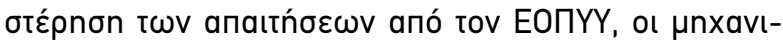

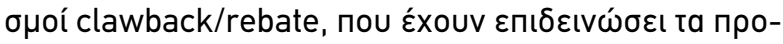

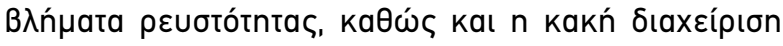

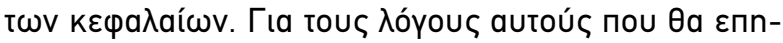

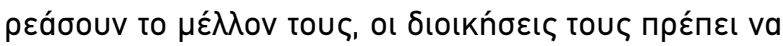

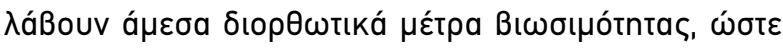

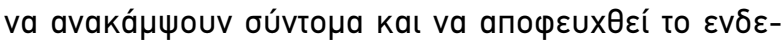
хó $\mu \varepsilon v o$ хрєокопі́ac.

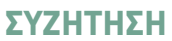

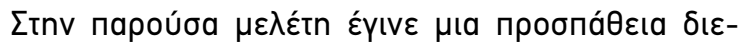

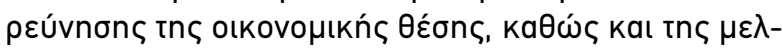

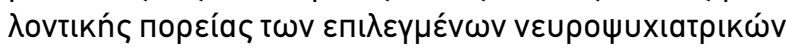

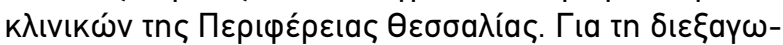

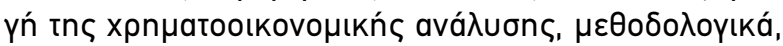

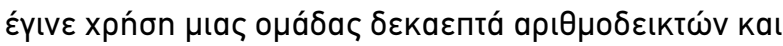

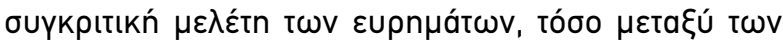

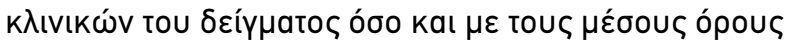

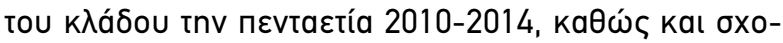

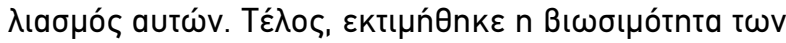

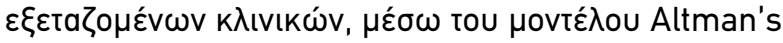

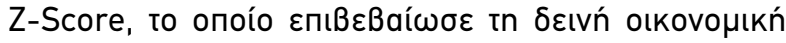

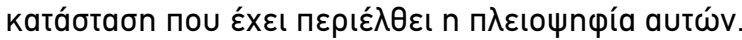

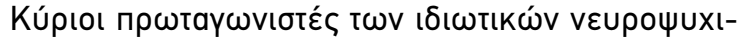

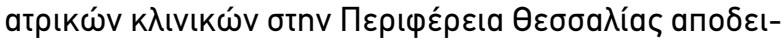

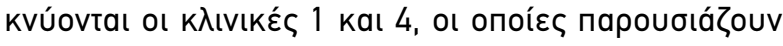

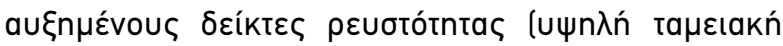

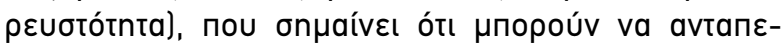

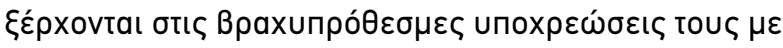

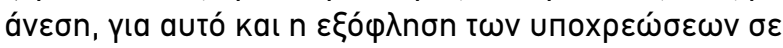

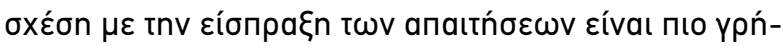

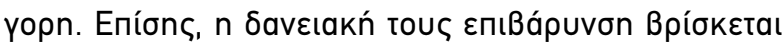

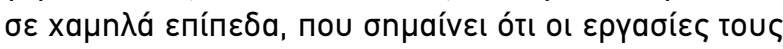

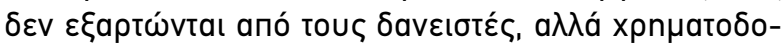

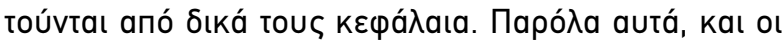

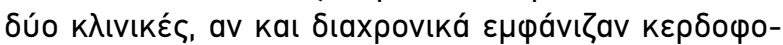

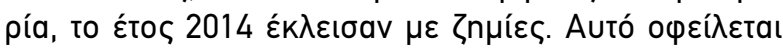

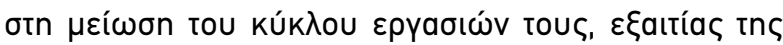

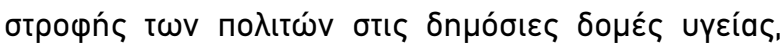




\section{EPEYNHTIKA APOPA}

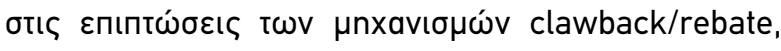

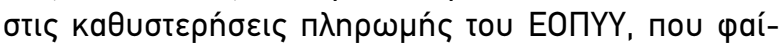

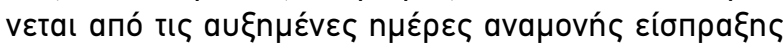

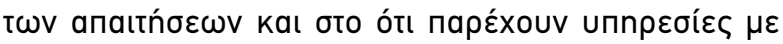

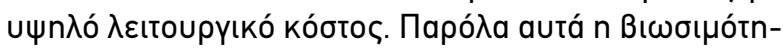
ta tn $\varsigma \lambda$ Ivıkń

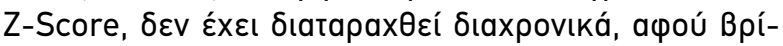

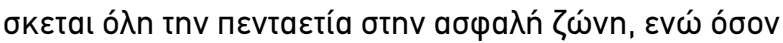

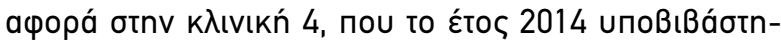

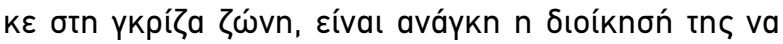

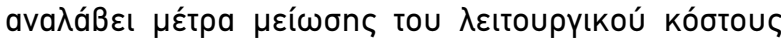
пapoxń

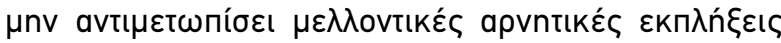
Bıwoluótntas.

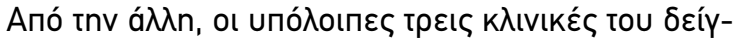

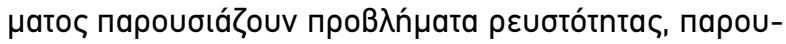

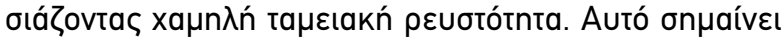

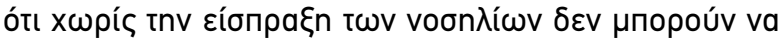

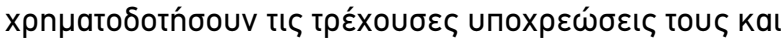

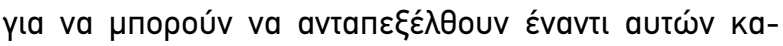

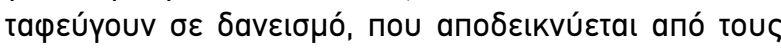

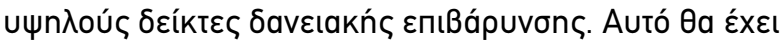

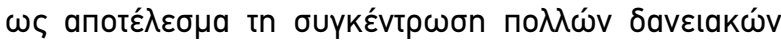

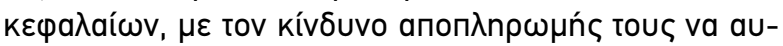

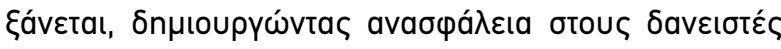

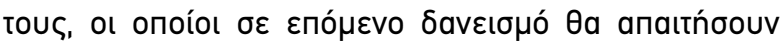

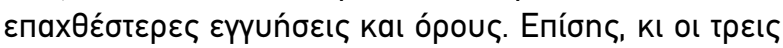

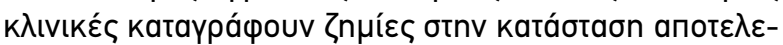

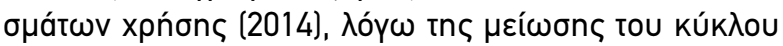

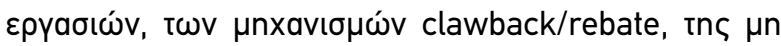

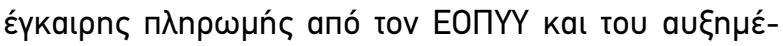

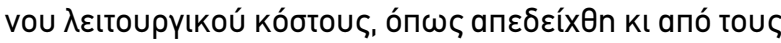

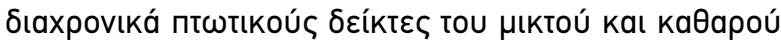

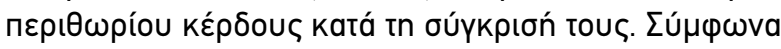

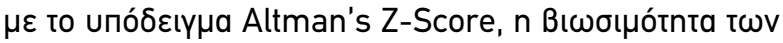

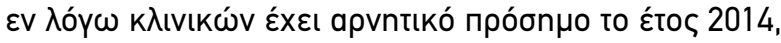

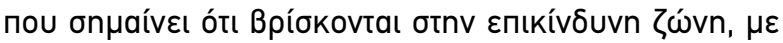

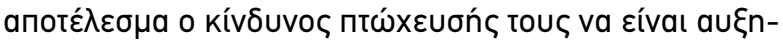

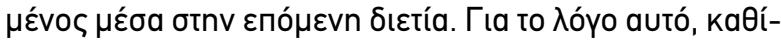

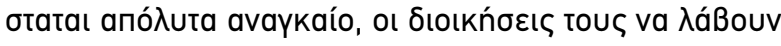

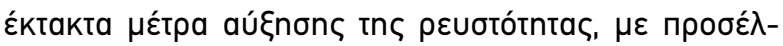

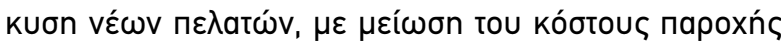

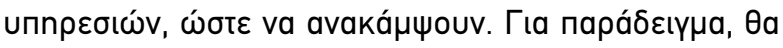

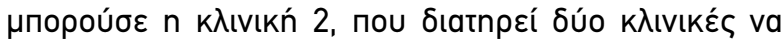

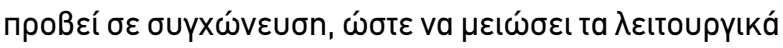

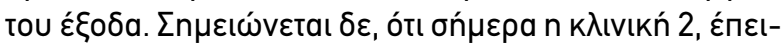

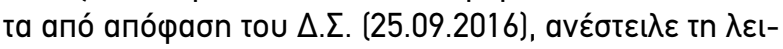

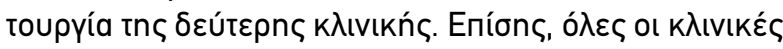

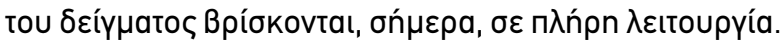

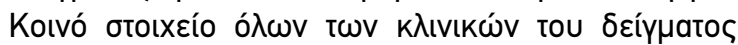

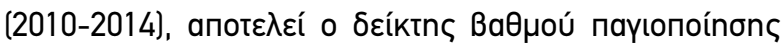

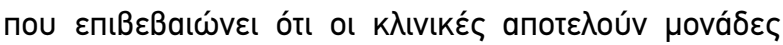

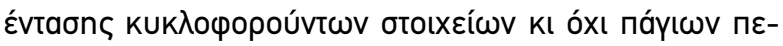

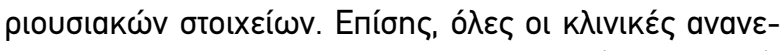

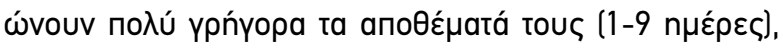

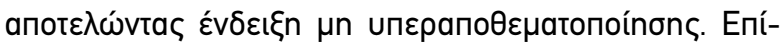

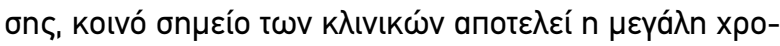

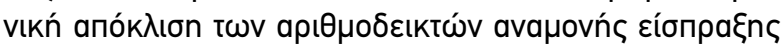

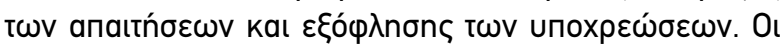

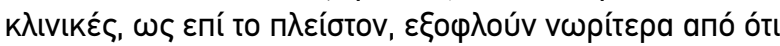

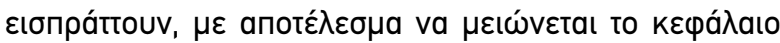

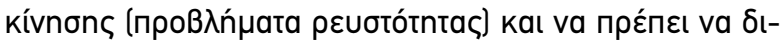

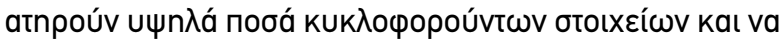

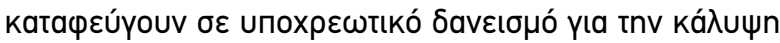

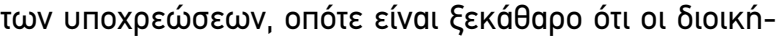

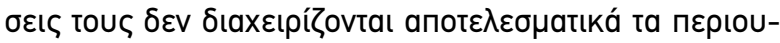

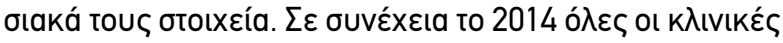

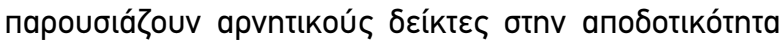

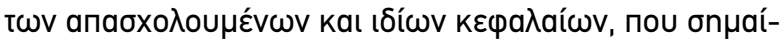

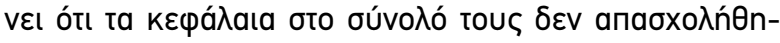

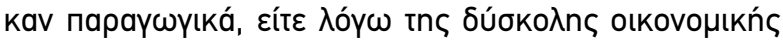

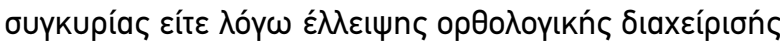

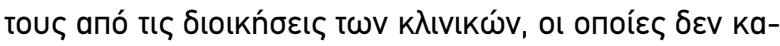

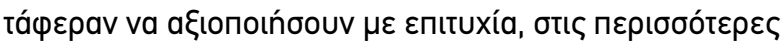

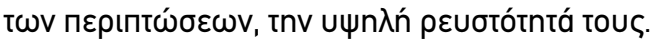

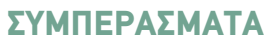

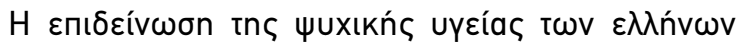

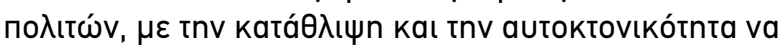

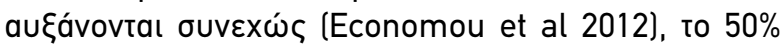

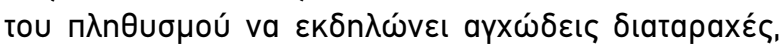

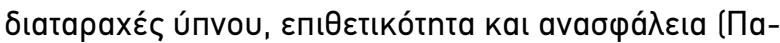

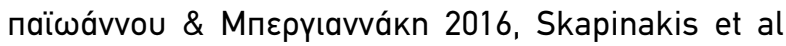

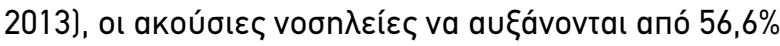

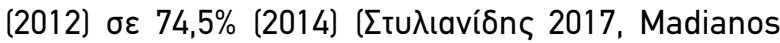

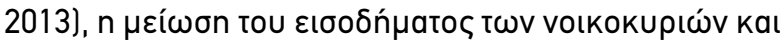

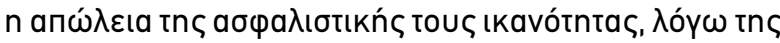

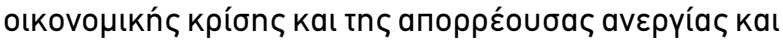

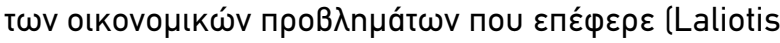
et al 2016, Simou \& Karageorgou 2014, Kupiónouגos

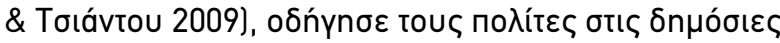

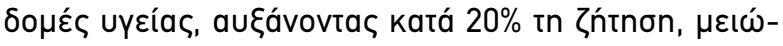

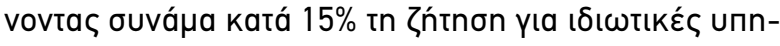

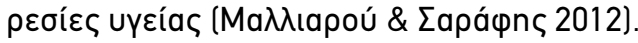

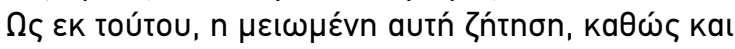

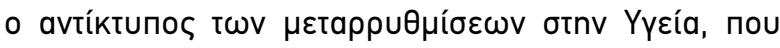

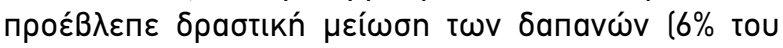

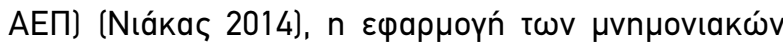

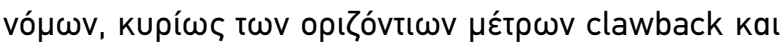

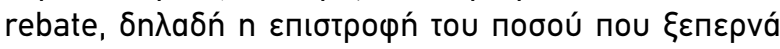

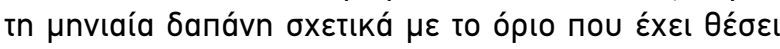

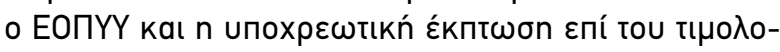

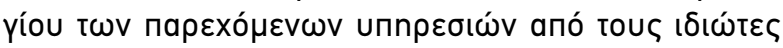

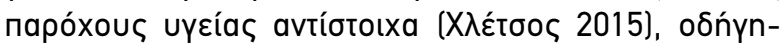

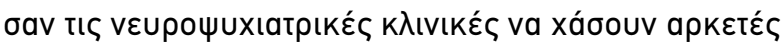

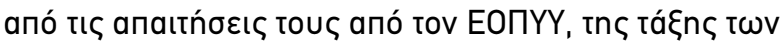




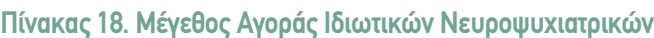

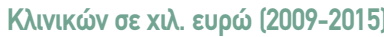

\begin{tabular}{|c|c|}
\hline ETOI & METEOOI ATOPAI \\
\hline $\mathbf{2 0 0 9}$ & 124.000 \\
\hline $\mathbf{2 0 1 0}$ & 121.000 \\
\hline $\mathbf{2 0 1 1}$ & 119.000 \\
\hline $\mathbf{2 0 1 2}$ & 102.000 \\
\hline $\mathbf{2 0 1 4}$ & 80.000 \\
\hline $\mathbf{2 0 1 5}$ (EkTínnon) & 65.000 \\
\hline
\end{tabular}

Ппүฑ́: ICAP Group (2015), Stochasis A.E. (2014)

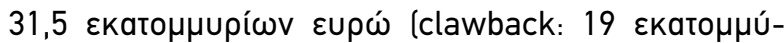

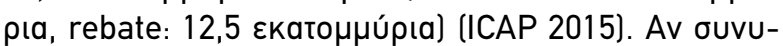

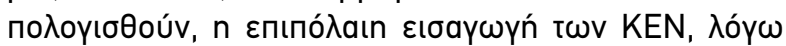

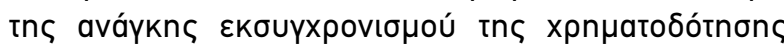

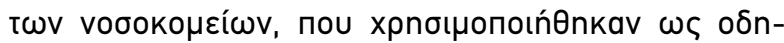

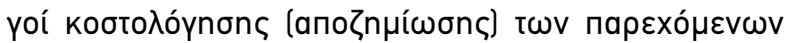

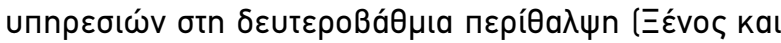

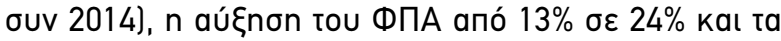

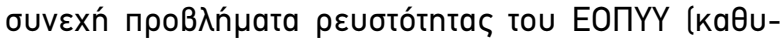

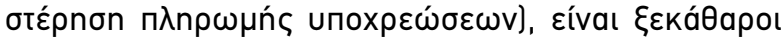

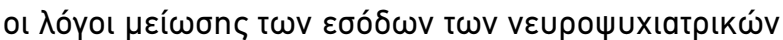

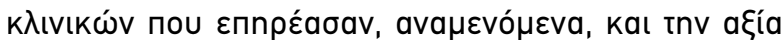

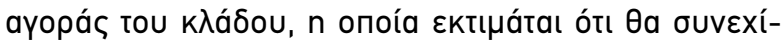

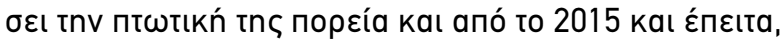

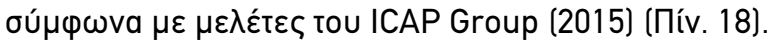

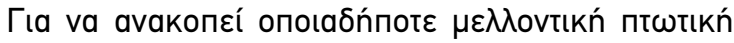

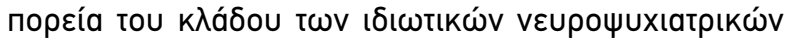

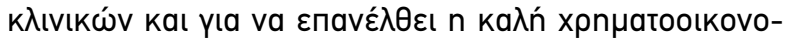

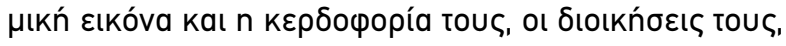

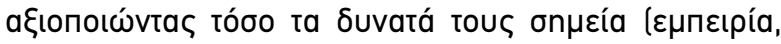

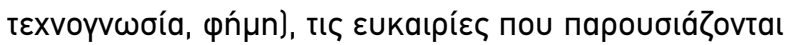

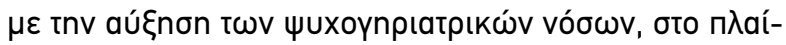
бı to

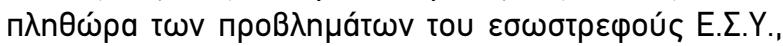

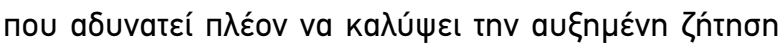

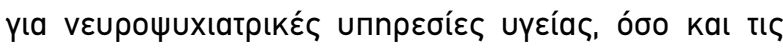

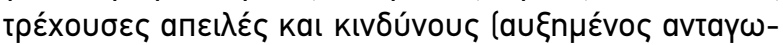

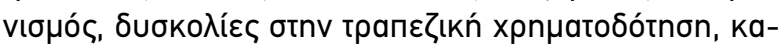

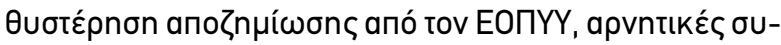

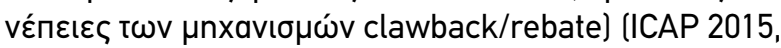

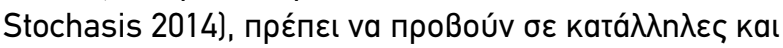

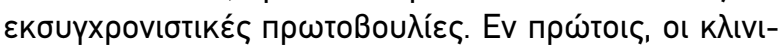

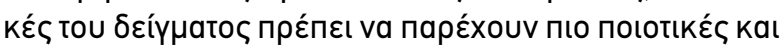

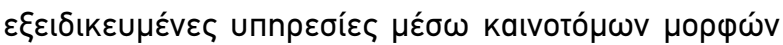

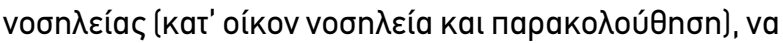

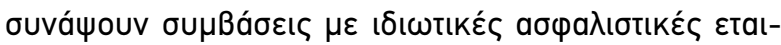

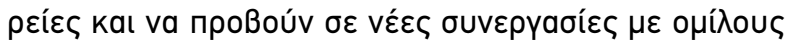

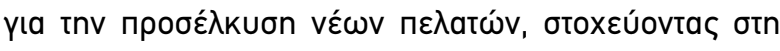

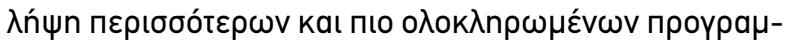

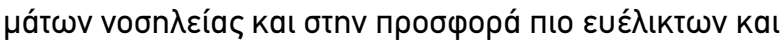

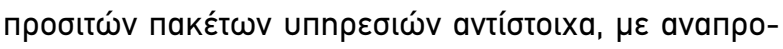

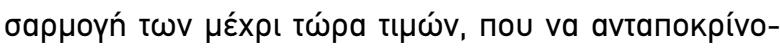

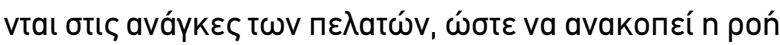

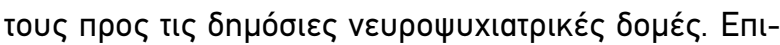

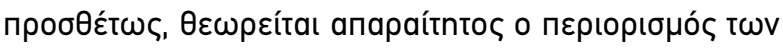

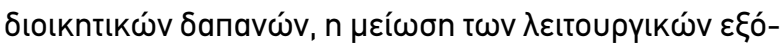

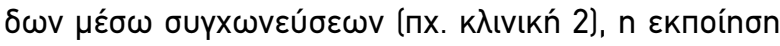

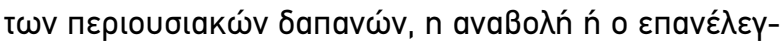

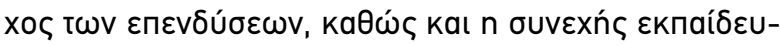

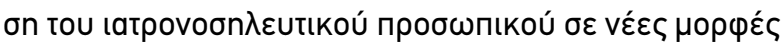

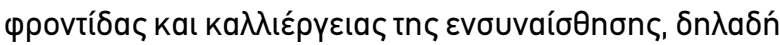

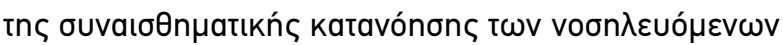

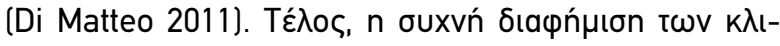

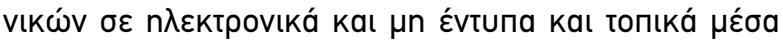

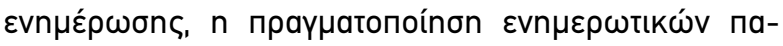

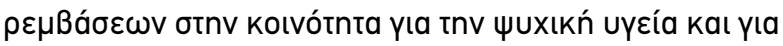

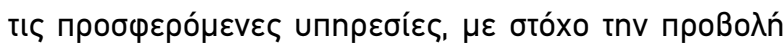

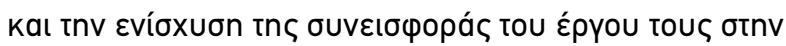

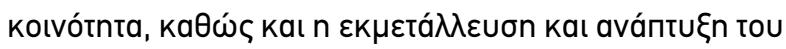

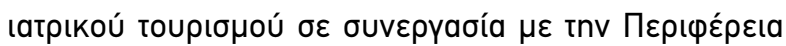

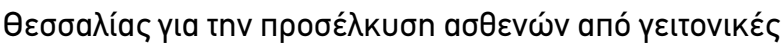

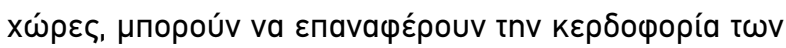

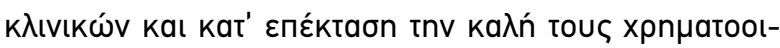

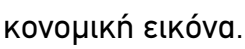

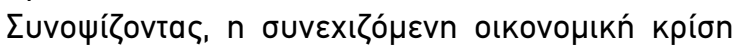

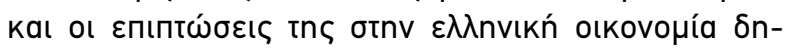

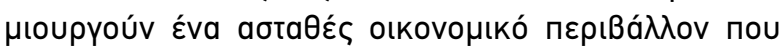

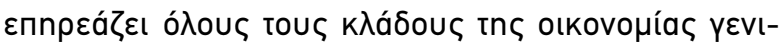

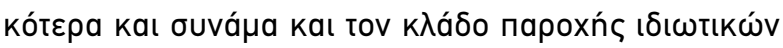

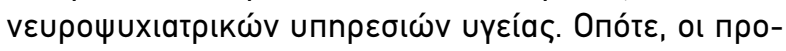

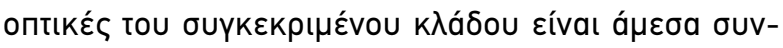
$\delta \varepsilon \delta \varepsilon \mu \varepsilon \dot{v} \varepsilon \varsigma \varsigma$ «

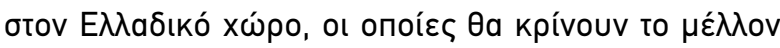

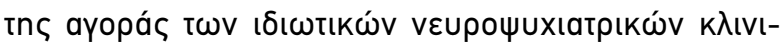

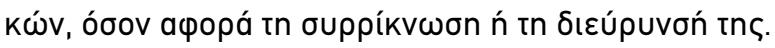

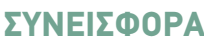

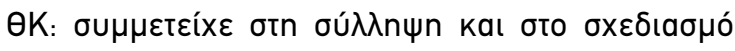

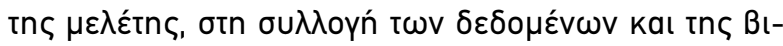

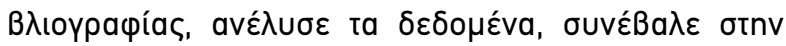

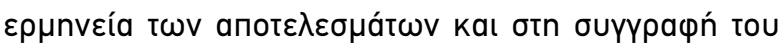

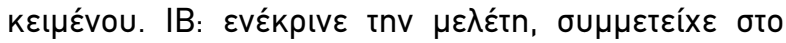

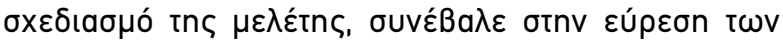

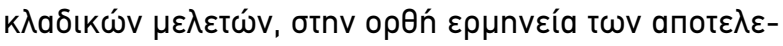

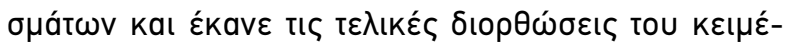

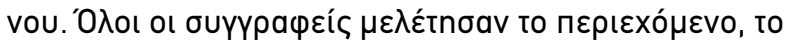

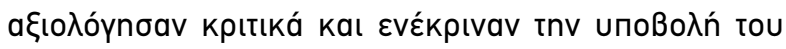

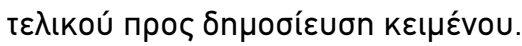




\section{ВІВАІОГРАФІА}

Altman E.I. (1968). Financial Ratios, Discriminant Analysis and the Prediction of Corporate Bankruptcy. The Journal of Finance 23(4):589-609

Aziz Adnan M. \& Humayon A.D. (2006). Predicting Corporate Bankruptcy: Where We Stand? Corporate Governance 6(1):18-33.

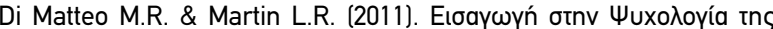

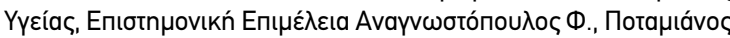

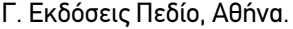

Economou C. (2012). The Performance of the Greek Healthcare System and the Economic Adjustment Programme: "Economic Crisis" versus "System-Specific Deficits" Driven Reform, Socia Theory 2(2):33-34

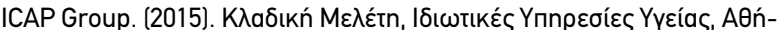
va.

Laliotis I., loannidis J. \& Stavropoulou C. (2016). Total and causespecific mortality before and after the onset of the Greek economic crisis: an interrupted time-series analysis. The Lancet Public Health 1(2):e56-e65

Madianos M. (2013). Economic crisis, mental health and psychiatric care: What happened to the "Psychiatric Reform" in Greece? Psychiatriki 24(1):13-14.

National Council of Educational Research and Training (2013), Accountancy Company Accounts and Analysis of Financial Statements, Textbook for Class XII, pp.: 239-240.

Scapinakis P., Bellos S., Koupidis S., Grammatikopoulos I., Theodorakis P. \& Mavreas V. (2013). Prevalence and sociodemographic associations of common mental health disorders in a nationally representative sample of the general population of Greece. BioMed Central Psychiatry 13(1):163.

Simou E. \& Koutsogeorgou E. (2014). Effects of the economic crisis on health and healthcare in Greece in the literature from 2009 to 2013: a systematic review. Health Policy 115(2-3):111-119.

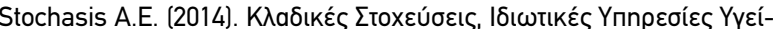
aç, AӨńva.

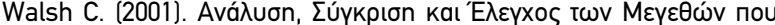

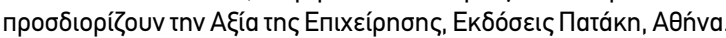

Walsh C. (2006). Key management Ratios - The clearest guide to the critical numbers that drive your business, Prentice Hall, 4th Edition, Great Britain.

Watkins A. (2000). Hospital Financial ratio classification patterns revisited: Upon considering nonfinancial information. Journal Accounting and Public Policy 19(1):73-95.

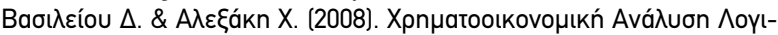

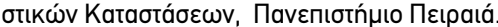

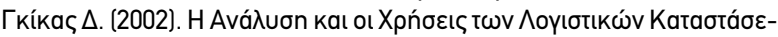

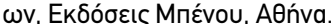

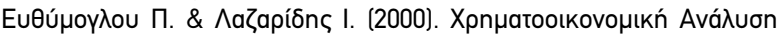

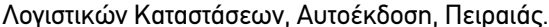

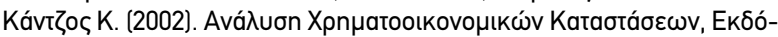

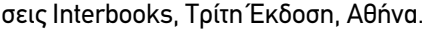

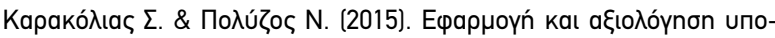

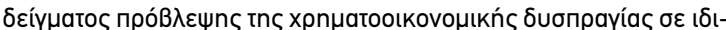

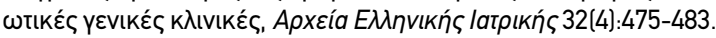

Kupıónou

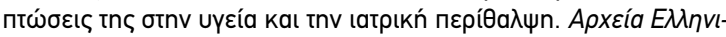
кńc latpıкńs 27(5):834-840.

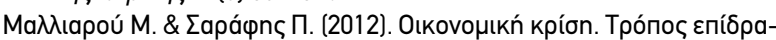

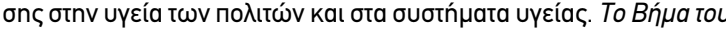

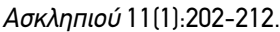

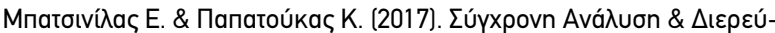

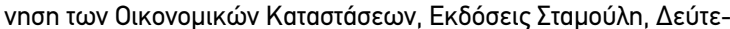

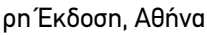

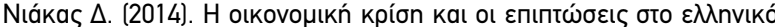

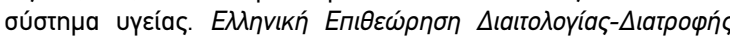
5(1):3-7.

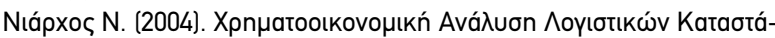

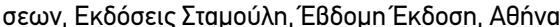

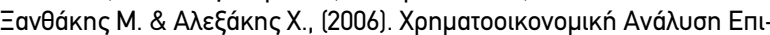

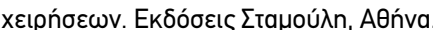

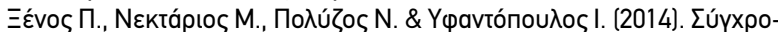

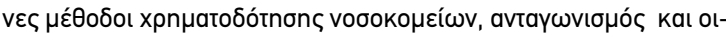

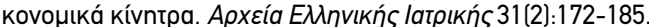

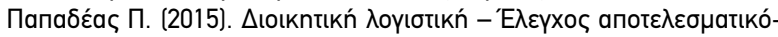

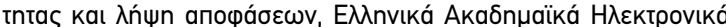

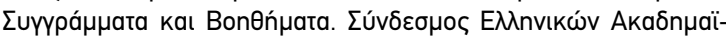

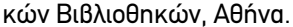

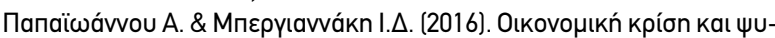

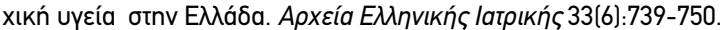

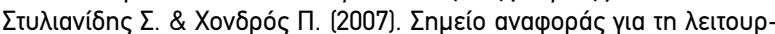

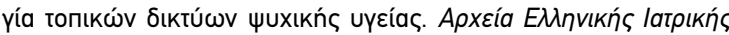
24(3):216-223

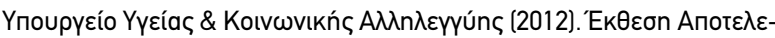

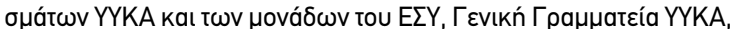
AӨńva.

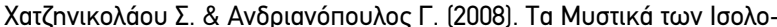

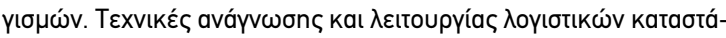

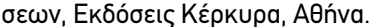

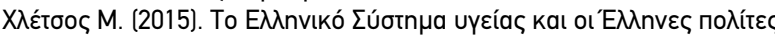

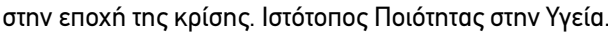

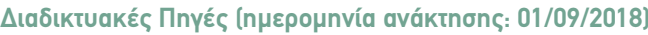

http://www.agiafotini-clinic.gr

http://www.agiosgeorgios-volos.gr

http://www.asklipiion.gr

https://www.businessregistry.gr/publicity/index

http://www.et.gr/index.php/anazitisi-me-stoixeia-etairias

http://www.euromedica.gr

http://www.ippokrateio.com

http://www.kastaliakarditsa.gr 


\title{
Financial Analysis of the Private Neuropsychiatric Clinics Sector in the Region of Thessaly
}

\author{
Theodosios Kokkios', loannis Varvatsoulakis ${ }^{2}$ \\ 1. Nurse, MSc in Management of Health Units, Mental Health Center - Nursing Unit of Agrinio. \\ 2. PhD, Associated Professor of Hellenic Open University.
}

\begin{abstract}
Background: The financial analysis of the financial balance sheets is a critical procedure and a "prophetic" technique that sheds light on its latent or non-fold aspects of an economic unit. It aims at analyzing, assessing and profoundly understand of its financial status, extracting useful conclusions that will help its management to take the appropriate decisions for its viability in the future.

Aim: The financial analysis of the largest private neuropsychiatric clinics in the region of Thessaly, Greece, for the period 2010-2014, during which the country faced severe economic destabilization and, within the framework of the fiscal stability programs to rationalize health expendure, significant changes had been instituted that had adversely affected their financial situation.

Methods: The selection of private neuropsychiatric clinics was based on their turnover in the year 2013. The sources of information and their financial data were the published financial statements, their corporate websites and the sectoral studies of the ICAP Group and Stochasis S.A. For the financial analysis, the ratios method was used and more specifically the liquidity, activity, profitability and capital structure financial ratios.

Results: The selected private neuropsychiatric clinics lost a significant part of their turnover, following the downward trend of the sector and their difficult financial situation that threatens their sustainability, in their majority, was also confirmed by the bankruptcy probability prediction model (Altman's Z-Score). The main causes of negative economic outcomes were the economic recession, the clawback/rebate mechanisms, the delay in compensation of the services provided by National Heatlhcare Organisation, as well as the decline in the citizens' income, which has compulsorily turned them to public health service structures.

Conclusions: The Management of the chosen clinics must receive development-type initiatives and exploit the opportunities, presented by the rise of mental illnesses and life expectancy, in order to improve their financial figures, increasing their liquidity, efficiency and profitability.
\end{abstract}

Keywords: Altman's Z-Score Model, Economic Crisis, Financial Analysis, Financial Ratios, Mental Health, Private Neuropsychiatric Clinics.

Corresponding Author: Theodosios Kokkios

e-mail: sakis.kokkios@gmail.com

Submission Date: 13.01.2019

Publication Date: January 2020

Citation: Kokkios T. \& Varvatsoulakis I. (2020). Financial analysis of the private neuropsychiatric clinics sector in the region of Thessaly. Hellenic Journal of Nursing Science 13(1): 41-57, DOI: https://doi.org/10.24283/hjns.202015 